\title{
MACRO POLICY REFORM, LABOUR MARKET, POVERTY AND INEQUALITY IN URBAN ETHIOPIA: A MICRO-SIMULATION APPROACH
}

\author{
Alemayehu Geda² and Alem Abereha
}

\begin{abstract}
Despite the liberalization program that Ethiopia embarked upon since 1992 aggregate indicators of poverty and inequality largely remained unchanged. This paper addresses why incomes and inequality largely remained stable at a time of fundamental changes in macroeconomic policy environment. We have used both data exploratory analysis as well as earning and occupational choice modelling, together with counterfactual simulation, to investigate this issue. The study showed that the absence of change in aggregate measure of poverty and inequality hides an enormous change that occurred across different income categories. This shows the importance of understanding the labour market to understand the policy propagation mechanism through which macro policy is expected to affect poverty. The study has show that although there seem to be limited change in poverty and inequality at aggregate level, there is significant change within and across categories of households. Thus different household are affected differently by the reform. The level and distribution of household incomes is found to depend on the structure of returns to labour and on the occupational choice the households made. Thus, policy effectiveness of poverty reduction policies could be achieved if we understand the workings of the labour market and how it affects both level and distribution of income across different categories of income \& sector.
\end{abstract}

\footnotetext{
${ }^{1}$ The final version of this article was submitted in September, 2006.

${ }^{2}$ Associate Professor, Dept of Economics, Addis Ababa University (corresponding author ag@ethionet.et). We thank the African Economic Research Consortium for financing this study. Any errors are ours
} 


\section{Introduction}

Governments in Africa and their development partners such as the World Bank and IMF are concerned with the issue of reducing poverty. Thus, since the 1980 they have deployed macro policy packages that are believed to help in addressing the challenge of reducing poverty. This took the form of Structural Adjustment Packages (SAP) in the 1980s and 1990s and now taking a 'new' form called Poverty Reductions Strategy Programs/Papers (PRSPs) or its new (or competitive version) 'the Millennium Development Goals' (MDGs). At the heart of these policy packages lie a set of macro polices, which can loosely be termed as 'liberalization and conservative monetary and fiscal policies' - or reform in short, that are believed to help the fight against poverty. One important analytical shortcoming of these efforts is lack of a link between macro policies employed and indicators of issues of poverty and inequality. In other words, we do not precisely know through which channels the deployed macro policies are supposed to affect poverty (perhaps the only exception being the presumption that stable macro environment is good for growth and hence for reducing poverty). One obvious channels through which macro polices may affect poverty is through its effect on the labour market and hence earnings form that market. Thus, characterization of the labour market in general and modelling how incomes are generated in this market in particular are key to understand the propagation mechanisms through which macro polices may affect poverty and inequality. This paper is aimed at exploring this issue using the Ethiopian household data and a micro simulation technique.

The rest of the study is organized as follows. In the next section, we present a brief review of the macroeconomic performance in post-reform Ethiopia. In section three, we will analyze the structure of employment and household income in urban Ethiopia. This section provides a description of the state of affairs and evolution of key labour market indicators using two rounds of a household survey undertaken in 1994 and 2004. In section four we will specify the models employed in the study and estimate their parameters. Using these models we have made a micro-simulation analysis of the impact of the reform on poverty and inequality in the same section. Section five will conclude the paper.

\section{The 1992 macro policy reform and poverty}

In 1991 the then-rebel forces (The Ethiopian People Revolutionary Democratic Front, EPRDF) overturned the 'socialist' military regime that ruled the country for a brutal 17 
years. With the support of the Breton Woods Institutions, the new regime began to carry out a liberalization policy in a typical Structural Adjustment Programme (SAPs) fashion. In terms of economic policy, this period witnessed a marked departure from the 'Socialist' control regime of the military era - the 'Derg' regime. The policy reform carried out includes:

a) Financial sector and labour market liberalization

b) Domestic and external trade liberalization

c) Liberalization of the product market, in particular the agricultural sector

d) Pursuing conservative fiscal and monetary policy: expenditure reduction and switching, tax reform, tight monetary policy, exchange rate and public sector reform.

Partly because of these policies and good weather outturn that is combined with a rising level of foreign aid, the growth performance in the post-reform period was much better than the previous regimes (see Table 1). Table 1 shows the evolution of major macro variables over the last four decades. The growth record is mixed but typically erratic and generally shows dismal performance of the economy although the postDerg period fairs better. The only good thing that can be read from Table 1 is the low level of inflation that shows remarkable stability. This is largely attributed to price regulation in the pre-reform (pre-1991) period and to the good macro performance and excellent weather outturn in much of the post-reform period (see Alemayehu 2005).

Table 1: Evolution of major macro aggregates (1962-2000)

\begin{tabular}{|c|c|c|c|c|c|c|c|}
\hline \multirow{2}{*}{$\begin{array}{l}\text { Gregorian Calendar } \\
\text { Ethiopian Calendar }\end{array}$} & \multicolumn{7}{|c|}{ 1962/66-1967/68-1972/3-1977/78-1982/83-1987/88- 1992/93- } \\
\hline & $\overline{1955-59}$ & $1960-64$ & 1965-69 & $1970-74$ & $1975-79$ & $1980-841$ & $\overline{1985-1992}$ \\
\hline Real GDP Growth & 4.7 & 4.0 & 1.3 & 2.3 & 3.7 & -0.01 & 5.7 \\
\hline Investment \% of GDP & 13.5 & 12.6 & 9.7 & 11.0 & 14.3 & 13.4 & 15.9 \\
\hline Saving as \% of GDP & 11.4 & 11.0 & 9.0 & 4.7 & 6.5 & 7.1 & 5.3 \\
\hline Export \& Import, \% of GDP & 24.1 & 22.1 & 26.5 & 29.1 & 26.0 & 20.2 & 37.8 \\
\hline Inflation* & & 1.7 & 11.4 & 10.7 & 3.4 & 11.8 & 3.8 \\
\hline Export as \% of Imports & 83.6 & 86.6 & 95.8 & 53.6 & 53.7 & 52.3 & 56.4 \\
\hline
\end{tabular}

Source: Owen Computation based on Ministry of Finance and Economic Development (MOFED) and Central Statistical Authority (CSA) data, various years.

${ }^{*}$ Based on mean of annual CPI rate.

In the wake of the 1992 reform, as shown above, the economy registered a real per capita income growth to the tune of about $3 \%$ per annum. For an economy recovering from prolonged civil war, drought and economic stagnation, this growth rate is miniscule. The latter is in particular true in the face of the colossal poverty the country 
harbours and the expectations by its people. As a result, it is difficult to see much change in welfare of people in Ethiopia after ten years of intense economic reform. Unfortunately even some of the gains witnessed at the early stage of the economic reform were lost with the onset of the 'border' war with Eritrea that lasted for about two years (1997/98-1999/2000). Thus, one of the worries that should be kept in mind, as illustrated in the Table 2 below, is that of the fragility of the Ethiopian macroeconomic condition and the possibility of policy reversals that could be triggered by a host of unforeseen emergency situations such as war/conflict, cut in aid, famine or other calamities and their implication for poverty reduction.

Table 2: Macroeconomic policy stance of Ethiopia (1991-2000)

\begin{tabular}{|c|c|c|c|c|c|c|c|c|c|}
\hline Policy Variable & $\frac{\stackrel{N}{\sigma}}{\stackrel{\sigma}{\sigma}}$ & $\begin{array}{l}\stackrel{m}{\sigma} \\
\stackrel{\text { N }}{\sigma} \\
\stackrel{\sigma}{-}\end{array}$ & $\begin{array}{l}\text { ম } \\
\stackrel{\text { m}}{\text { g }} \\
\stackrel{-}{-}\end{array}$ & 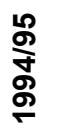 & $\begin{array}{l}\stackrel{\circ}{\circ} \\
\stackrel{5}{\circ} \\
\stackrel{\circ}{\circ}\end{array}$ & $\begin{array}{l}\stackrel{ }{\circ} \\
\text { ğ } \\
\stackrel{\sigma}{-}\end{array}$ & $\begin{array}{l}\stackrel{\infty}{\sigma} \\
\stackrel{\sigma}{\sigma} \\
\stackrel{\sigma}{\square}\end{array}$ & 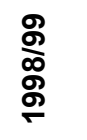 & $\begin{array}{l}\text { 용 } \\
\text { ㅇ } \\
\stackrel{\circ}{-}\end{array}$ \\
\hline $\begin{array}{l}\text { Per capita GDP growth } \\
\text { rate }\end{array}$ & -8.3 & 9.8 & -0.6 & 4 & 8.4 & 3 & -2.7 & 4.5 & 2.2 \\
\hline \multicolumn{10}{|l|}{ Fiscal Policy } \\
\hline Deficit/GDP (\%) & -9.7 & -7.5 & -11.3 & -7.3 & -7.9 & -5.1 & -7.2 & -12.2 & -15.1 \\
\hline Revenue/GDP (\%) & 10.8 & 12.0 & 14.0 & 17.2 & 18.0 & 18.8 & 18.0 & 17.9 & 18.4 \\
\hline \multicolumn{10}{|l|}{ Monetary Policy } \\
\hline Seignior age ${ }^{\star}$ & 16.9 & 4.77 & 8.53 & 18.9 & -1.97 & 0.28 & 13.9 & -0.48 & 9.66 \\
\hline Inflation & 21.0 & 10.0 & 1.2 & 13.4 & 0.9 & -6.4 & 3.6 & 3.9 & 4.2 \\
\hline \multicolumn{10}{|l|}{ Exchange Rate Policy } \\
\hline $\operatorname{REER}^{* *}(\%)$ & na & 77.1 & -14.8 & 1.7 & -8.2 & 1.2 & -0.9 & -1.0 & -6.4 \\
\hline PMP (\%)\# & 201.9 & 65.0 & 22.0 & 16.8 & 20.5 & 10.0 & 0.0 & 1.0 & 1.0 \\
\hline
\end{tabular}

Note: REER = Real Effective Exchange Rate; PMP = Parallel Market Premium ${ }^{*}$ Estimated as the difference between broad money and real GDP growth rates. $\quad * * 1979 / 80=100$, \# PMP=Parallel market premium

Sources: Authors computation based on MoFED and National Bank of Ethiopia data.

The above table gives some indication on the link between macroeconomic policy stance and economic growth. The latter in turn believed to be linked to poverty. In the period when the policy stance showed significant improvement (1994/951996/97), the per capita GDP growth rate was positive, more or less robust and stable. When the policy stance was weak, on the other hand, so was the growth rate in per capita GDP. In fact, the available evidence also indicates that poverty behaved in like manner during this period (See Bigsten et al, 2001, Alemayehu, Abebe and Weeks, 2002). Thus, there is some evidence suggesting that good macroeconomic policy stance is associated with good growth performance and hence reduction of poverty. However, we do not know the path or propagating channel through which macro policies does affect level of poverty. One possible channel is the labour market, which is the subject of this study and pursued at length in the rest of the 
study. The concept of labour market is however problematic in the African setup and generally refers to the urban labour market. Our focus is thus on the urban labour market.

Most existing studies on the evolution of poverty and inequality focus on analysis of consumption. Hence, they tell us little about the mechanisms through which changes in the market and macro policy environment affect income. Alternative approaches such as static decomposition methodologies and dominance tests have important shortcomings too. First, decompositions on one dimension do not control for any other dimension/characteristics of households. Second, the decompositions are of scalar measures, and therefore "waste" information on how the entire distributions differ (along their support). Finally, even to the extent that one is prepared to treat inequality between subgroups defined, say, by age or education, as being driven by those attributes - rather than by correlates - the share of total inequality attributed to that partition tells us nothing of whether it is the distribution of the characteristics (or asset), or the structure of its returns that matters.

In this study, we adopt a micro-simulation methodology that does not suffer any of the aforementioned shortcomings. Using this methodology, we will analyze the evolution of poverty and inequality in urban Ethiopia using two sets of urban household surveys that covered 1500 households in each year and conducted by the Department of Economics of Addis Ababa University in seven urban centres in Ethiopia for the years 1994 and $2000^{3}$. Hence, we will be able to compare the effects of major policy changes that occurred in the 1990s by comparing the structure of household incomes in 1994 with the structure that prevailed 5-6 years later to detect and explain the major shifts in structure of incomes, which we have hypothesized to be linked with SAPs.

\section{The urban labour market, poverty and inequality in Ethiopia}

We begin from the working hypothesis that changes in poverty and inequality is likely to be closely associated with changes in the labour market condition. Thus, understanding the labour market helps to identify the channels through which macro policies may affect earnings from the labour market which in turn affect conditions of poverty and inequality. The basic idea of the micro-simulation is to isolate the effect of each of the main determinants of the changes in poverty and inequality and associate these changes to the process of macroeconomic adjustment and stabilization, and to

\footnotetext{
${ }^{3}$ See Bigsten and Shimeles (2005) about the methodology of the data collection and other related details.
} 
the set of liberalization policies which we loosely termed as 'macro policy reform'. The methodology consists of creating a counterfactual in the form of labour market parameters representing, among other, the employment and remuneration structure, which would prevail if the labour market structure would be different than observed in the year that we take as a point of departure for the analysis (cf. Paes de Barros and Leite 1998; Paes d'e Barros 1999 cited in Vos and Taylor, 2002; Frenkel and González 1999, Vos and Taylor 2002). This counterfactual may be obtained by either model simulations to generate a case of 'with-and-without' or by taking the structure prevailing in another year and imposing it on another. Following the latter approach, we take the Ethiopian micro data of one year, 2000, and simulate what poverty and inequality would have been, had the labour market structure remained what it was in 1994. The two years are selected based on availability of household data in years close to the beginning of the reform period which is the year 1992 and as recently as possible so as to see the effect of these reforms on poverty and inequality.

\subsection{The structure of employment and household income}

Table 3 summarizes the major structural features of the labour market in urban areas in 1994 and 2000. The most notable point is the absence of any change in the unemployment rate, which had been about 33 percent in both years. The other important changes are the increase in the share of wage employment by about 4.5 percentage points, and the decline in the share of public sector employment by about 9.0 percentage points. The latter seems consistent with expenditure reduction aspect of the policy reform. The composition of the labour force and the employed population in terms of sex, age and educational composition had also been stable (see Table 4). The only exception is the decline in the share of persons with no education, by 3 percentage points in the labour force and 6 percentage points among the employed.

Table 3: Characteristics of the labour market: 1994 and 2000 (households)

\begin{tabular}{lrr}
\hline & $\mathbf{1 9 9 4}$ & $\mathbf{2 0 0 0}$ \\
\hline Percent able-bodied & 61.81 & 65.88 \\
Participation rate & 57 & 53.72 \\
Unemployment rate & 33.03 & 32.93 \\
Self-employment rate & 19.34 & 14.87 \\
of which Female HH. & 37.97 & 37.27 \\
Wage-employment rate & 47.63 & 52.2 \\
of which: Public sector & 52.57 & 43.52 \\
\hline
\end{tabular}


Table 4: Characteristics of the labour force: 1994 and 2000

\begin{tabular}{lcccr}
\hline & \multicolumn{2}{c}{ Economically Active } & \multicolumn{2}{c}{ Employed } \\
\hline \multicolumn{1}{l}{ Education } & $\mathbf{1 9 9 4}$ & $\mathbf{2 0 0 0}$ & $\mathbf{1 9 9 4}$ & $\mathbf{2 0 0 0}$ \\
\hline None & & & & \\
\hline Primary & 32.3 & 29.01 & 32.3 & 36.09 \\
\hline Junior secondary. & 9.95 & 10.89 & 9.95 & 10.99 \\
\hline Senior secondary & 15.33 & 16.7 & 15.33 & 14.31 \\
\hline Post-secondary & 29.94 & 32.39 & 29.94 & 25.3 \\
\hline Age-group & 12.48 & 11.02 & 12.48 & 13.31 \\
\hline $15-24$ & & & & \\
\hline $25-34$ & 32.91 & 31.44 & 32.91 & 19.25 \\
\hline $35-44$ & 27.93 & 30.49 & 27.93 & 28.93 \\
\hline $45-54$ & 19.54 & 19.27 & 19.54 & 25.81 \\
\hline $55-64$ & 12.24 & 11.7 & 12.24 & 15.83 \\
\hline Sex & 4.74 & 4.6 & 4.74 & 6.45 \\
\hline Female & & & & \\
\hline Male & 46.83 & 45.03 & 46.83 & 44.15 \\
\hline
\end{tabular}

Table 5 shows the distribution of households by source of income. The share of households that had income from wage employment increased from about 63 percent to about 68 percent, while the share that had self-employment income ${ }^{4}$ declined from 36 percent to 25 percent. The share of households that received 'other' (non-labour) incomes increased from about 45 percent to 52 percent. The share of households that depended on income from 'wage-employment only' was about 32 percent in 1994 and about 34 percent in 2000, while the share of those that depended on income from self-employment only declined from about 15 percent to about 9 percent. The share of households that depended on 'other' incomes was about 13 percent in 1994 and 17 percent in 2000.

Share of households with members working in the wage sector shows almost no change. The share of households with no wage income is slightly lower in $2000-34$ percent vis-à-vis 38 percent. The share of households with one wage-employed member is about 39 percent in 1994 and 42 percent in 2000, and that of households with two or more wage-employed members is about 24 percent in both years, respectively. Considering all sample households, median household income from wage employment was Birr 144 (per annum) in 1994 and 189 in 2000 and mean income 322 and 379 , respectively (the average exchange rate during the period was

\footnotetext{
${ }^{4}$ Self-employment income is defined as income that accrues to (i) employers/owners of private businesses; (ii) own-account workers; and (iii) those operating female household businesses. All other labour income is considered wage income.
} 
about $\$ 1.00=$ Birr 8.60). Considering households with positive wage incomes only, median income from wage employment was 350.00 in 1994 and 393 in 2000. The interquartile range, an indicator of equality, changed from 471 in 1994 to 526 in 2000.

Table 5: Sources of household income in 1994 and 2000 (percent of households)

\begin{tabular}{ccr}
\hline & $\mathbf{1 9 9 4}$ & $\mathbf{2 0 0 0}$ \\
\hline Wage-employment income & 63.81 & 67.85 \\
Wage-employment only & 32.24 & 33.86 \\
Self-employment income & 35.52 & 25.43 \\
Self-employment only & 14.78 & 8.96 \\
Other income & 45.26 & 51.65 \\
Other income only & 13.27 & 16.47 \\
\hline
\end{tabular}

Median household income from self-employment among households with selfemployed members declined by about 39 percent - from Birr 200.00 in 1994 to Birr 123.00 in 2000 . The decline was even larger in terms of mean household income from self-employment, which fell by half from Birr 2,476.00 in 1,994 to Birr 1,260.00 in 2,000 . The distribution of self-employment income is more skewed to the right than that of wage income, and this concentration of incomes in the lower end increased in 2000. It seems reasonable to infer that the reform period has been strongly associated with negative outcome for self-employed households. We have examined the three categories of income in detail below.

Median wage income was unchanged between the rounds at about 250.00 Birr, while mean incomes changed from about Birr 331.00 to Birr 386. The stagnation in median incomes, however, hides the changes that occurred at the lower and higher ends of the wage distribution. A more disaggregated comparison of changes in income across the rounds indicates that the largest percentage change in wage income occurred in the first (lowest) and fifth (richest) quintiles, and the smallest change in the third quintile. This pattern of change has important implications for the evolution of indicators of poverty and inequality. Given the observed level of head-count ratios, larger changes in poverty indicators would have occurred if changes in incomes were concentrated around the middle of the distribution instead of the extremes. In simple words the growth occurred doesn't seem to be pro-poor or distributional neutral as can be read from Table 6 and Figure 1 below (see Alemayehu, Abebe and Weeks, 2002). 
Inequality in individual-level wage incomes over the whole sample has changed only slightly. The change in inequality indicated by alternative indicators differed at this level of aggregation. A careful comparison of the indicators showed that those that give greater weight to the left-hand side of the distribution indicated a decline, while others indicated no change or an increase in inequality. Further investigation of changes in inequality by levels of income shows that the aggregate results hide interesting patterns of change at different levels of income. Inequality has declined substantially at the lower end of the distribution, remained unchanged in the middle, and increased at the upper end. Inequality among the lower-earning 40 percent of wage-workers declined (Gini coefficient falling from 34 to 27) while it increased in the remaining 60 percent (Gini coefficient rising from 32 to 36). The changes were such that inequality among the lower-earning 40 percent has become lower not only relative to its level in 1994, but also relative to the higher-earning 60 percent. Consistency between different indicators is also achieved once the analysis is done with income disaggregated by levels (see Appendix Tables).

Table 6: Level and inequality of wage incomes: changes between 1994 and 2000

\begin{tabular}{rrrrrrrrrrrrrr}
\hline & \multicolumn{4}{c}{ Gini } & \multicolumn{4}{c}{ Mean (Birr) } & \multicolumn{4}{c}{ Median (birr) } \\
\cline { 2 - 13 } & $\mathbf{1 9 9 4}$ & $\mathbf{2 0 0 0}$ & Change & \multicolumn{1}{c}{$\%$} & $\mathbf{1 9 9 4}$ & $\mathbf{2 0 0 0}$ & Change & \% & $\mathbf{1 9 9 4}$ & $\mathbf{2 0 0 0}$ & Change & $\%$ \\
\hline Q1 & 30.96 & 23.71 & -7.25 & -23.41 & 42.45 & 64.11 & 21.66 & 51.02 & 38.44 & 65.99 & 27.55 & 71.66 \\
Q2 & 10.69 & 10.15 & -0.54 & -5.04 & 136.99 & 146.20 & 9.21 & 6.72 & 134.56 & 142.99 & 8.43 & 6.27 \\
Q3 & 8.95 & 9.38 & 0.43 & 4.81 & 249.42 & 254.84 & 5.41 & 2.17 & 250.00 & 246.50 & -3.50 & -1.40 \\
Q4 & 8.31 & 8.75 & 0.44 & 5.28 & 405.55 & 448.94 & 43.39 & 10.70 & 400.00 & 441.70 & 41.70 & 10.43 \\
Q5 & 23.56 & 27.10 & 3.54 & 15.02 & 857.08 & 1025.08 & 168.00 & 19.60 & 689.70 & 759.49 & 69.79 & 10.12 \\
\hline
\end{tabular}

Figure 1 (a) and (b): Changes in the distribution of wage income per month (1994-2000, by quintile) 


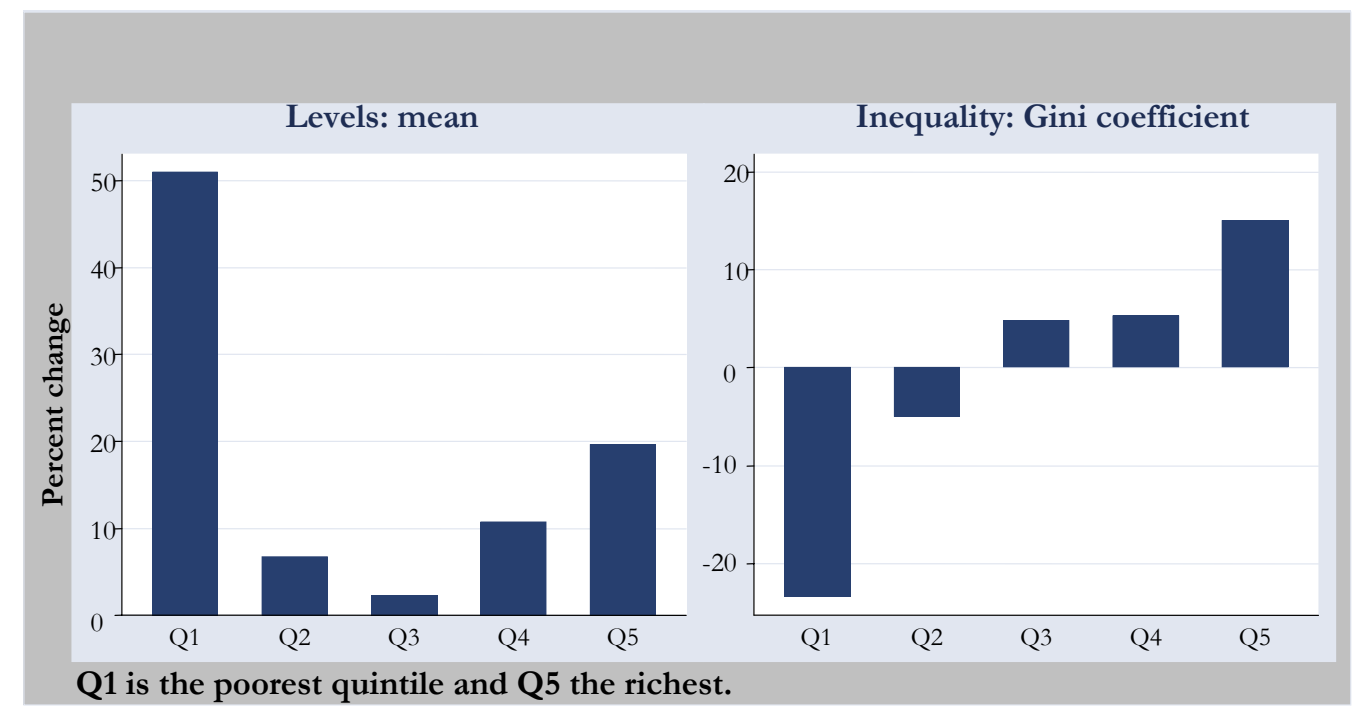

Figure 2(a) and (b): Kernel density estimates: Wage income (1994 and 2000)

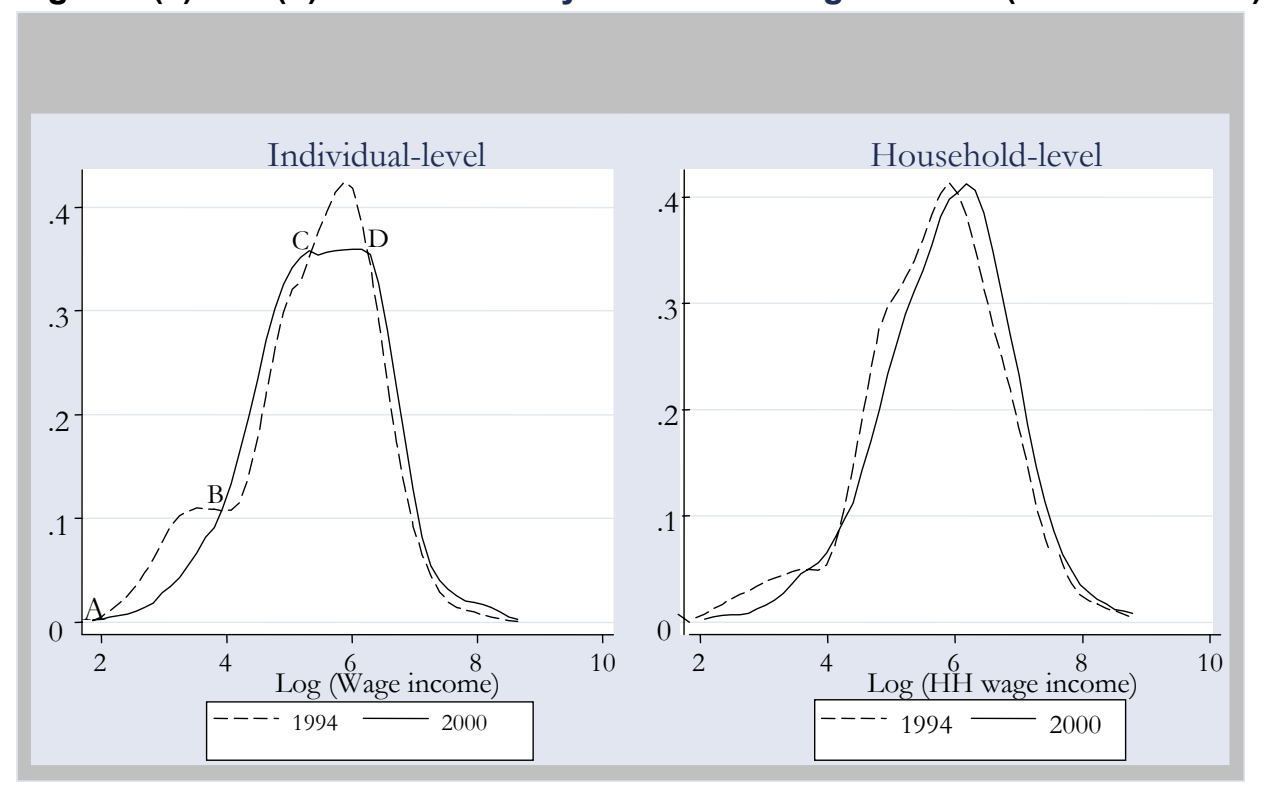

(ii) Self-employment income

Median self-employment income declined by about 33 percent from Birr 218.33 in 1994 to 145.66 in 2000, while mean incomes declined by about 20 percent from Birr 1029.40 to 823.70 . The share of individuals in self-employment who report losses has also declined from 15 percent in 1994 to 9 percent in 2000. This suggests that there was a compression of self-employment incomes -the possibility of getting large 
profits as well as that of incurring large losses has fallen in 2000. This is confirmed by the fall in the standard deviation of self-employment income and its inter-quartile range, both indicators of inequality. The largest decline in mean/median incomes occurred at the centre of the distribution - the third quintile - in which average incomes in 2000 are less than a third of their level in 1994. The pattern of change differs greatly from that of wage income, in which income changed more in the extremes of the distribution and the change is upwards.

Table 7: Level and inequality of self-employment incomes: changes between 1994 and 2000

\begin{tabular}{rrrrrrrrrrrrrr}
\hline & \multicolumn{4}{c}{ Gini } & \multicolumn{4}{c}{ Mean (Birr) } & \multicolumn{4}{c}{ Median (Birr) } \\
\cline { 2 - 14 } & $\mathbf{1 9 9 4}$ & $\mathbf{2 0 0 0}$ & Change & \multicolumn{1}{c}{$\%$} & $\mathbf{1 9 9 4}$ & $\mathbf{2 0 0 0}$ & Change & \% & $\mathbf{1 9 9 4}$ & $\mathbf{2 0 0 0}$ & Change & \% \\
\hline Q1 & 32.99 & 33.98 & 0.99 & 3.00 & 27.55 & 23.58 & -3.98 & -14.43 & 29.89 & 20.73 & -9.16 & -30.64 \\
Q2 & 15.23 & 9.21 & -6.02 & -39.51 & 102.49 & 73.97 & -28.53 & -27.83 & 100.00 & 79.66 & -20.34 & -20.34 \\
Q3 & 14.91 & 13.30 & -1.61 & -10.81 & 248.89 & 154.09 & -94.80 & -38.09 & 227.37 & 148.36 & -79.01 & -34.75 \\
Q4 & 15.38 & 24.62 & 9.24 & 60.04 & 642.66 & 524.57 & -118.09 & -18.38 & 614.48 & 468.51 & -145.97 & -23.76 \\
Q5 & 50.10 & 37.95 & -12.15 & -24.24 & 4158.66 & 3406.88 & -751.77 & -18.08 & 1974.46 & 2294.10 & 319.64 & 16.19 \\
\hline
\end{tabular}

Inequality in individual-level self-employment incomes over the whole sample has changed only slightly. Inequality seems to have declined in the middle and top; and increased in the bottom. Generally, however, it is stable. Combined with the decline in average income, this implies that the poor is getting poorer (see Figures 2 and 3 ).

Figure 3(a) and (b): Changes in the distribution of self-employment income per month (1994-2000, by quintile)

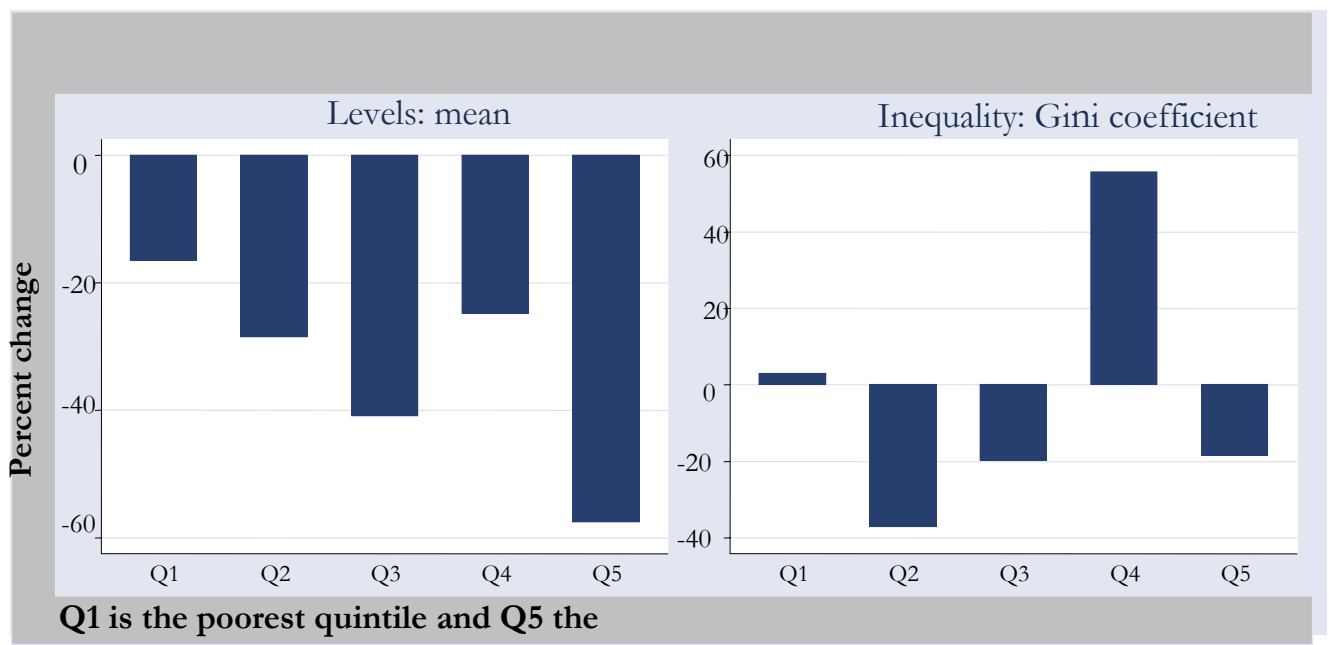

Figure 3(c) and (d): Kernel density estimates: SE income (1994 and 2000) 


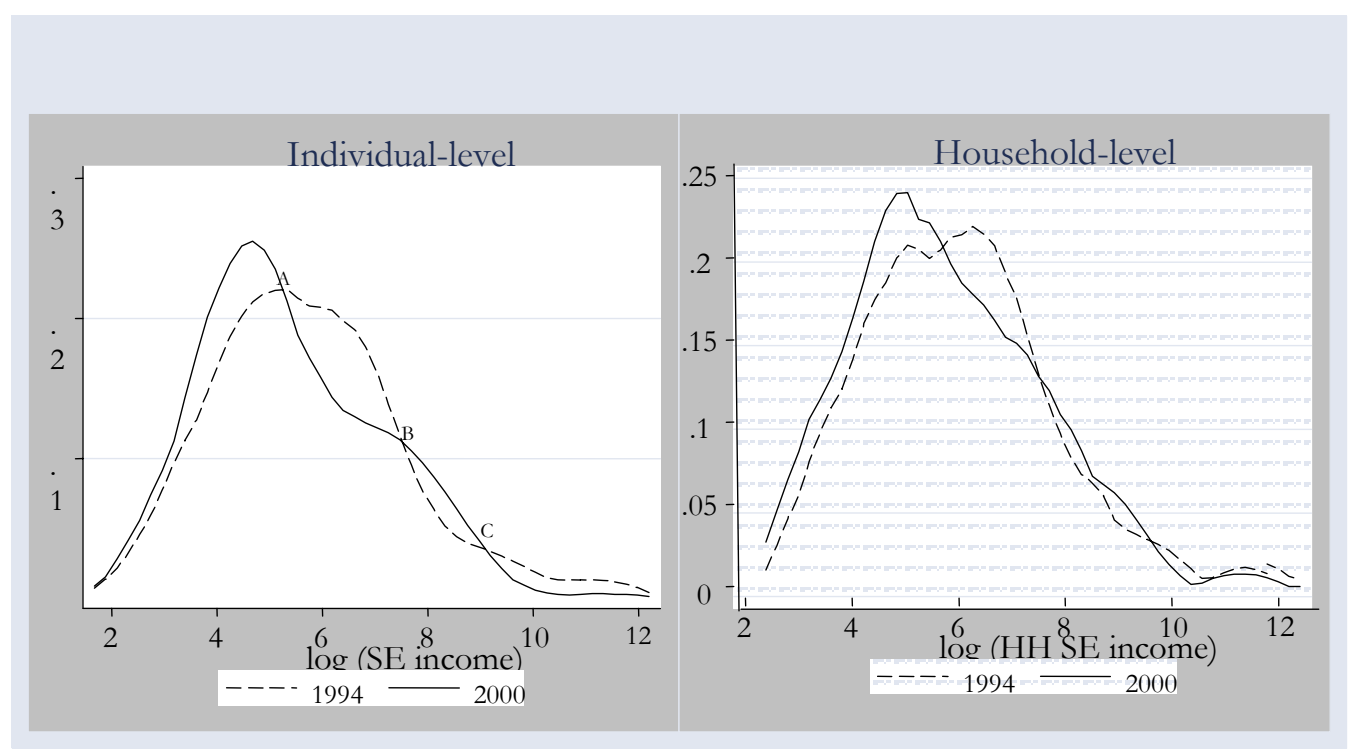

(iii) Other income

Other income is defined as a residual category and includes income from assets (such as house rental), transfers, labour incomes from activities other than the main activity, and income from child labour. The share of households reporting income in this category increased from 44.1 percent to 49.9 percent. The level of 'other' income seems not to have changed much, with median 'other' income being 82.5 Birr in 1994 and 87.8 Birr in 2000 and mean 'other' income being 202.0 Birr in 1994 and 204.9 in 2000. Considering all sample households, mean 'other' income per household increased from 89.1 Birr in 1994 to 102.3 Birr in 2000. As mean 'other' income among households that have positive 'other' income is unchanged, the rise in mean income is largely explained by the 'participation effect'. Inequality in 'other' income has remained constant at Birr 60.58 and 59.01 in 1994 and 2000, respectively (see Table 8 and Figure 4).

Table 8: Level and inequality of 'other' incomes: changes between 1994 and $2000^{5}$

\begin{tabular}{rrrrrrrrrrrrrr}
\hline & \multicolumn{3}{c}{ Gini coefficient } & \multicolumn{4}{c}{ Mean (Birr) } & \multicolumn{4}{c}{ Median (Birr) } \\
\cline { 2 - 17 } & $\mathbf{1 9 9 4}$ & $\mathbf{2 0 0 0}$ & Change & \% & $\mathbf{1 9 9 4}$ & $\mathbf{2 0 0 0}$ & Change & \% & $\mathbf{1 9 9 4}$ & $\mathbf{2 0 0 0}$ & Change & \% \\
\hline Q1 & 31.32 & 34.35 & 3.02 & 9.65 & 10.16 & 10.62 & 0.47 & 4.58 & 9.88 & 9.63 & -0.24 & -2.44 \\
Q2 & 16.43 & 15.34 & -1.09 & -6.61 & 38.62 & 38.80 & 0.19 & 0.48 & 39.93 & 38.52 & -1.42 & -3.55 \\
Q3 & 9.10 & 10.43 & 1.33 & 14.61 & 81.94 & 86.43 & 4.49 & 5.48 & 82.50 & 87.99 & 5.49 & 6.66 \\
Q4 & 11.44 & 12.73 & 1.29 & 11.25 & 156.84 & 171.94 & 15.10 & 9.63 & 157.56 & 166.01 & 8.45 & 5.36 \\
Q5 & 32.85 & 27.76 & -5.10 & -15.52 & 491.51 & 482.74 & -8.77 & -1.78 & 383.17 & 394.38 & 11.21 & 2.93 \\
\hline
\end{tabular}

\footnotetext{
${ }^{5}$ The results are calculated after the top and bottom 1 percent of observations are trimmed.
} 
Figure 4(a) and (b): Changes in the distribution of 'other' income per month (1994-2000, by quintile)

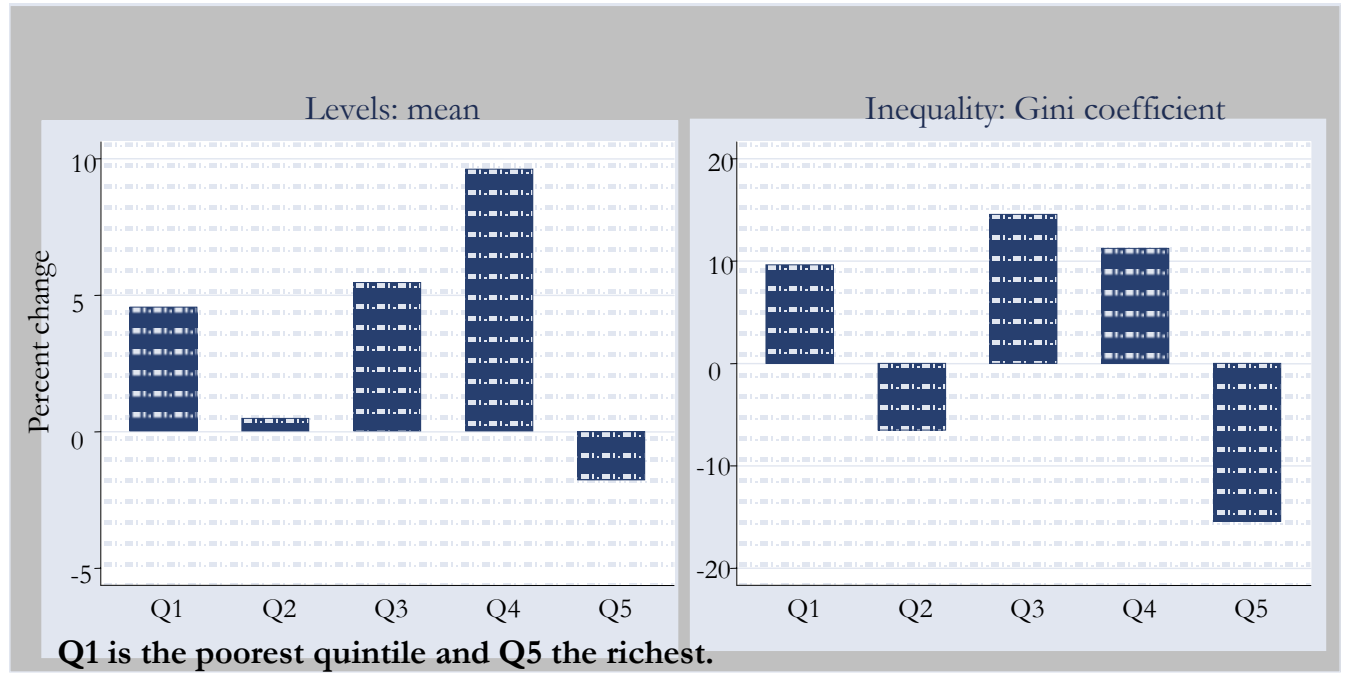

Figure 4(c): Kernel density estimates: 'other' income (household-level)

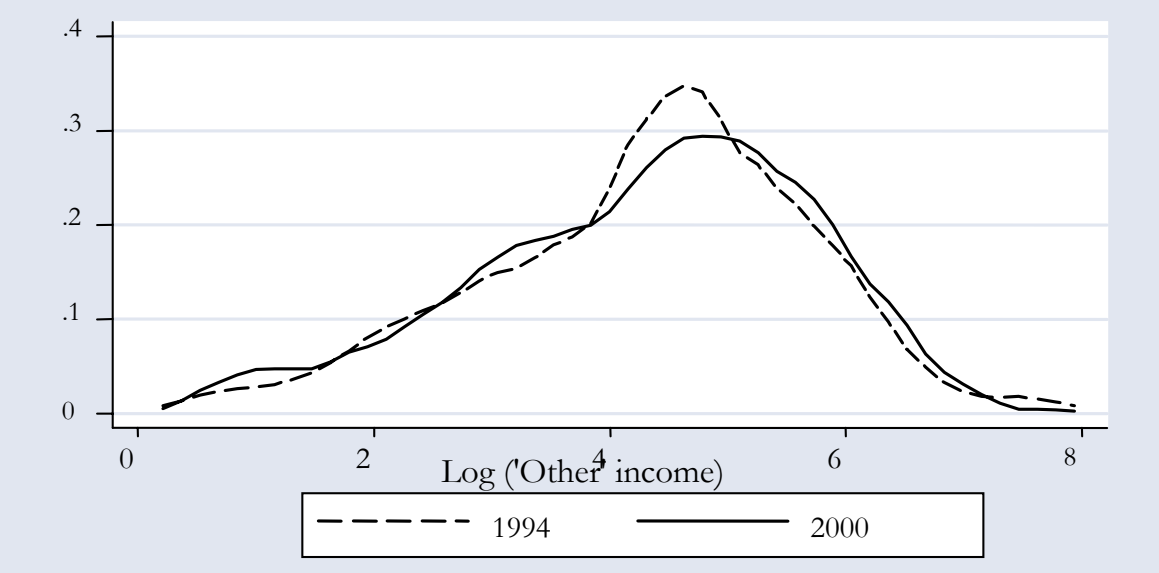

\subsection{Changes in poverty and inequality}

As this period was the aftermath of stabilization and launching of structural adjustment program, one would expect larger changes in income levels, poverty and inequality, especially in urban areas. This expectation, however, is not borne out by our data. Between 1994 and 2000, poverty headcounts declined only slightly from about 52 percent to about 47 percent. Since there was no change in mean per capita household income (which was about Birr 137.00 in both periods), the observed slight 
decline in headcount ratios seems to be the results of redistribution that favoured lower income groups (see Table 8 and Figure 5). However, since the observed changes in mean and median incomes are statistically insignificant, we focus on explaining why incomes remained stable at a time of fundamental changes in macroeconomic policy/environment.

The absence of significant micro responses to macroeconomic policy change may reflect the absence of significant real changes in the opportunities and risks faced by households or inability to respond to changes in the macroeconomic environment. On the other hand, aggregate indicators might fail to reflect great upheavals in household fortunes if (i) changes in components of household income move in different directions and cancel out each other, or (ii) changes in incomes of different categories of households move in opposing directions and cancel out each other. Microeconomic simulation models, by virtue of their ability to model moments of distributions beyond the first moments, can shed more light on these issues. In the next section, we employ microeconomic simulation models to decompose changes in household incomes so as to explain changes in poverty (or lack thereof) in urban Ethiopia.

Table 9: Poverty and inequality in 1994 and 2000

\begin{tabular}{lrrrlllr}
\hline Income levels (Birr) & \multicolumn{1}{c}{$\mathbf{1 9 9 4}$} & \multicolumn{1}{c}{$\mathbf{2 0 0 0}$} & Change & Inequality & $\mathbf{1 9 9 4}$ & $\mathbf{2 0 0 0}$ & Change \\
\hline Mean & 136.91 & 137.63 & 0.52 & Gini coefficient & 0.6069 & 0.5720 & -5.75 \\
P10 & 12.76 & 13.96 & $\mathbf{9} .40$ & Gen entropy $(\varepsilon=-1)$ & 2.0472 & 1.6418 & -19.80 \\
P25 & 28.13 & 33.59 & 19.40 & Gen entropy $(\varepsilon=0)$ & 0.7572 & 0.6625 & -12.50 \\
P50 & 66.13 & 74.97 & 13.36 & Theil index & 0.6953 & 0.6039 & -13.15 \\
P75 & 152.51 & 157.87 & 3.52 & Gen entropy $(\varepsilon=2)$ & 1.2049 & 0.9779 & -18.84 \\
P90 & 320.30 & 319.52 & -0.24 & Std dev of loges & 1.2776 & 1.2066 & -5.55 \\
Poverty levels & & & & Coef of variation & 1.5498 & 1.3946 & -10.01 \\
Headcount ratio & 51.46 & 47.23 & -8.20 & & & & \\
Poverty-gap ratio & 28.23 & 24.63 & -12.75 & & & & \\
FGT, a=2 & 19.23 & 16.44 & -14.52 & & & & \\
Watts index & 54.38 & 46.36 & -14.75 & & & & \\
Sen index & 36.17 & 32.10 & -11.26 & & & & \\
\hline
\end{tabular}

Figure 5: Kernel density estimates of percapita household income (1994 \& 2000 


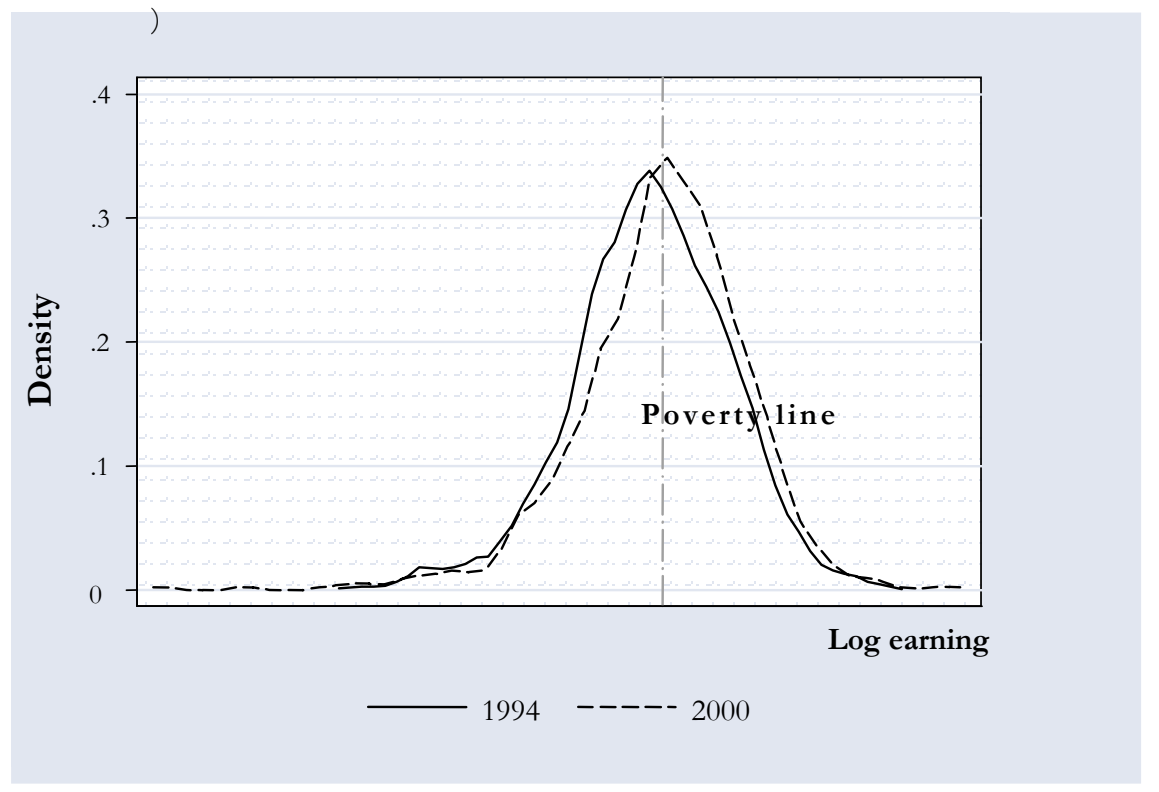

\section{Modelling the urban labour market and micro- simulation results}

\subsection{The model}

The analysis so far shows that although there seem to be limited change in poverty and inequality at aggregate level, there is significant change within and across categories of households. The distribution of household incomes depends on the structure of returns and on the characteristics of employed household members. To capture the effect of these, we draw on earning models. The distribution of household incomes also depends on their participation and occupational choices as well as on decisions concerning the size and composition of the family - labour market chrematistics. These will also need to be modelled. Modelling the latter will have the additional benefit of capturing the fact that changes in some personal characteristics, such as education, affect household incomes through more than one channel. We pursued this at two levels of modelling.

We began the modelling by aggregating income of all household members across sectors. We will first model and estimate participation and occupational choice parameters, parameters of earning determination in the labour market, and obtain estimates of unobserved earning determinants and their standard errors. That is, the firstlevel modelling comprises generating household income using the following equation: 


$$
y_{h i}=\frac{1}{n_{h i}}\left[\sum_{i=1}^{n_{h}} \sum_{j=1}^{J} I_{h i}^{j} y_{h i}^{j}+y_{0}\right]
$$

where $I$ is an index function, $j$ is activities, $i$ is individuals, and $h$ is households.

This equation simply adds up labour incomes for all household members, across the sectors into which we assume the labour market is segmented. These may comprise of a wage sector, a smallholder farm sector, non-farm self-employment sector and non-participation/unemployment. The final term, $y_{0}$, in equation (1) comprises all reported non-labour incomes accruing to the household. Having this, we will model income distribution using the following Mincerian earning equation:

$$
\log y_{h i}^{j}=\alpha_{j}+\mathbf{x}_{h i} \beta_{j}+\varepsilon_{i}
$$

These are a set of standard semi-logarithmic Mincerian earnings equations. The dependent variable is the logarithm of the monthly income $y$ (before taxes and transfers), and the arguments $(\mathbf{x})$ are human capital proxies, other personal characteristics, and some characteristics of the job. This is followed by modelling of participation and occupation choice using the following equation:

$$
\operatorname{Pr}\{j=s\}=P^{s}\left(Z_{h i}, \lambda\right)=\frac{e^{Z_{h i} \lambda_{s}}}{e^{Z_{h i} \lambda_{s}}+\sum_{j \neq s} e^{Z_{h i} \lambda_{j}}}
$$

Where $Z$ and $\lambda$ are personal and household characteristics, respectively.

Equations (3) models the choice of occupation (into wage employment, smallholder farming, non-farm self-employment, or inactivity) by means of a discrete choice model specifically, a multinomial logit - which estimates the probability of choice of each occupation as a function of a set of regional, family and personal variables characteristics

\subsection{Estimation results}

Determination of earnings

The first set of equations in our model includes two standard semi-logarithmic Mincerian earnings equations, one for the self-employed and another for the wage employed - two categories found to have distinct pattern of change. The form of the earnings equations given as equation (2) above is used: 


$$
\log y_{h i}^{j}=\alpha_{j}+\mathbf{x}_{h i} \beta_{j}+\varepsilon_{i}
$$

where $\log y$ is the logarithm of the monthly wage (before taxes and transfers) for wage workers and gross earnings for the self-employed, and $\mathbf{x}$ is a vector containing age, sex, level of education and whether person lives in Addis Ababa or not. In the wage equation, we have included a dummy indicating whether the person is employed in the public sector to capture the premium, if any, to public sector employment. In the equation for the self-employed, we included the number of paid workers as a proxy for the size of person's business. A dummy indicating whether the type of business is a female-household business - an informal sector activity that is said to be a coping strategy for the extremely poor - is also included. The estimated result of these are shown in Table 100. The coefficients in both equations and years have the expected signs. The first notable point that has important implications for our purpose is the direction of change in the mean minimum income (as represented by the constants): mean minimum income in the wage sector rose while it declined in the selfemployment sector, this is consistent with the descriptive analysis in section two above.

In the wage sector, there has been a decline between the years in the premiums associated with being male, being a public-sector employee as well the premiums associated with experience and the level of education. This may relate to the lack of incentive-compatible pay system in public sector. In the self-employment sector, the disadvantages arising from operating being female household businesses have become bigger, while the premiums associated with larger business have increased substantially. The effect of being male, which was insignificant in 1994, had become positive in 2000. If female-headed business is a good proxy for the poor in the informal sector, the reform is associated with relative negative outcome for this group. The effect of residence in Addis Ababa turned insignificant in 2000 from having a negative effect in 1994.

Table 10: Returns to labour in self employment and wage employment

\begin{tabular}{lcccc}
\hline & \multicolumn{2}{c}{ Wage-employment } & \multicolumn{2}{c}{ Self-employment } \\
\cline { 2 - 5 } & $\mathbf{1 9 9 4}$ & $\mathbf{2 0 0 0}$ & $\mathbf{1 9 9 4}$ & $\mathbf{2 0 0 0}$ \\
\hline Constant & $4.6634 \ddagger$ & $5.2062 \ddagger$ & $6.6882 \ddagger$ & $5.3066 \ddagger$ \\
Age & $0.0954 \ddagger$ & $0.0830 \ddagger$ & $0.0748^{\star}$ & $0.0824^{*}$ \\
Age-squared & $-0.0009 \ddagger$ & $-0.0008 \ddagger$ & $-0.0007^{\star}$ & $-0.0008^{*}$ \\
Male & $0.5017 \ddagger$ & $0.4572 \ddagger$ & 0.1378 & $0.7531^{*}$ \\
Public sector & $0.2537 \ddagger$ & $0.2228 \ddagger$ & - & - \\
Fem. HH Bus. & - & - & $-1.5246 \ddagger$ & $-1.0382^{*}$ \\
\hline
\end{tabular}




\begin{tabular}{|c|c|c|c|c|}
\hline Addis Ababa & 0.0320 & 0.0067 & $-0.4954^{* *}$ & -0.0442 \\
\hline \multicolumn{5}{|l|}{ Education } \\
\hline Primary & $0.3878 \ddagger$ & $0.3111 \ddagger$ & $0.5058^{* *}$ & $1.4776 \ddagger$ \\
\hline Junior secondary & $0.5776 \ddagger$ & $0.4116 \ddagger$ & $0.7485^{\star *}$ & 0.7698 \\
\hline Senior secondary & $0.9101 \ddagger$ & $0.8775 \ddagger$ & $1.1004 \ddagger$ & $0.9232^{*}$ \\
\hline Post-secondary. & $1.4559 \ddagger$ & $1.3192 \ddagger$ & $1.1310 \ddagger$ & $1.4351^{* *}$ \\
\hline \multicolumn{5}{|c|}{ Number of paid workers } \\
\hline One & - & - & $0.7387^{* *}$ & $1.2175^{\star *}$ \\
\hline Two or more & - & - & $0.9467^{* *}$ & $1.5482^{\star *}$ \\
\hline Sample & 1187 & 772 & 406 & 199 \\
\hline Pseudo $R^{2}$ & 0.5709 & 0.4607 & 0.3815 & 0.4576 \\
\hline
\end{tabular}

Note $^{*} \quad p<0.05 ;{ }^{* *} p<0.01 ; \ddagger p<0.001$

Participation and occupational choice

The choice of occupation (into wage employment, smallholder farming, non-farm selfemployment, or inactivity) is modelled by means of a discrete choice model - a multinomial logit - which is given as equation 3 above and reproduced here,

$$
\operatorname{Pr}\{j=s\}=P^{s}\left(Z_{h i}, \lambda\right)=\frac{e^{Z_{h i} \lambda_{s}}}{e^{Z_{h i} \lambda_{s}}+\sum_{j \neq s} e^{Z_{h i} \lambda_{j}}}
$$

Our occupational choice of able-bodied individuals is categorized into four: inactivity, unemployment, self-employment and wage employment. Since inactivity is considered as one choice, this approach models labour supply of household members as well. The comparison group for our occupational choice model is the able-bodied population that is not economically active. In terms of type of employment, we define non-wage employment as consisting of (i) employers/owners of private businesses; (ii) own-account workers; and (iii) those operating female household businesses. All others employment is considered wage employment.

Labour supply/occupational choice by members is modelled as a function of his/her personal characteristics and some household characteristics. Specifically, the subvector of $Z$ containing personal characteristics includes sex, age, educational level, a dummy indicating whether the person is head of household or not, a dummy indicating whether the person is the spouse of the head of household or not, and a dummy indicating whether the person is a student or not. The household characteristics sub-vector contains a dummy indicating whether head of the household is employed or not and the share of employed household members (excluding the person). The resulting estimated equation is shown in Table 11. The 
significance level and the sign of the coefficients in the two rounds are generally similar, but there is a difference in the magnitude of the coefficients. The result generally shows that the choice of wage employment is largely determined by educational characteristic. It can also be read from Table 11 that, once a household is in school he/she is engaged either in wage employment or is unemployed - showing the absence of limited relationship between schooling and self-employment.

Table 11: Occupational choice model - estimated coefficients

\begin{tabular}{|c|c|c|c|c|c|c|}
\hline & \multicolumn{2}{|c|}{ Unemployment } & \multicolumn{2}{|c|}{ Self-employment } & \multicolumn{2}{|c|}{ Wage employment } \\
\hline & 1994 & 2000 & 1994 & 2000 & 1994 & 2000 \\
\hline Age & -0.0139 & -0.0253 & 0.0464 & 0.0298 & $0.1027 \ddagger$ & $0.1125 \ddagger$ \\
\hline Age-Squared & -0.0004 & -0.0004 & $-0.0006^{*}$ & -0.0004 & $-0.0015 \ddagger$ & $-0.0016 \ddagger$ \\
\hline Sex & $1.2136 \ddagger$ & $2.0584 \ddagger$ & $1.2080 \ddagger$ & $1.8169 \ddagger$ & $1.5555 \ddagger$ & $2.1659 \ddagger$ \\
\hline Is head & $-1.0926 \ddagger$ & $-1.1208 \ddagger$ & $1.0249 \ddagger$ & 0.5735 & 0.2004 & 0.0438 \\
\hline Is spouse & $-3.5972 \ddagger$ & $-2.9607 \ddagger$ & $-0.8523 \ddagger$ & $-0.9737^{* *}$ & $-1.8907 \ddagger$ & $-1.6492 \ddagger$ \\
\hline Is student & -44.367 & -41.524 & -42.267 & -39.756 & -43.781 & -40.553 \\
\hline Head is employed & -0.2791 & -0.3006 & $-0.6985 \ddagger$ & -0.3579 & $-0.4665^{\star *}$ & -0.1374 \\
\hline \multicolumn{7}{|l|}{ Education } \\
\hline Primary & $0.8880 \ddagger$ & 0.5165 & 0.114 & -0.1959 & 0.271 & 0.2317 \\
\hline Junior secondary & $1.4798 \ddagger$ & $1.1437 \ddagger$ & -0.2158 & -0.0706 & 0.3358 & $0.5138^{*}$ \\
\hline Senior secondary & $2.5881 \ddagger$ & $1.8174 \ddagger$ & -0.154 & 0.297 & $1.0499 \ddagger$ & $1.0989 \ddagger$ \\
\hline Post-secondary. & $3.3219 \ddagger$ & $2.7007 \ddagger$ & $1.2773^{\star *}$ & $1.5077^{* *}$ & $3.2795 \ddagger$ & $3.0549 \ddagger$ \\
\hline $\begin{array}{l}\text { Share employed } \\
\text { members }\end{array}$ & $-1.5685 \ddagger$ & $-2.2822 \ddagger$ & $-3.2163 \ddagger$ & $-3.6714 \ddagger$ & $-2.1735 \ddagger$ & $-2.9214 \ddagger$ \\
\hline Constant & 0.4541 & 0.8517 & $-1.1918^{*}$ & -1.3249 & $-0.9975^{*}$ & $-1.6558^{* *}$ \\
\hline Statistics & 1994 & 2000 & & & & \\
\hline Sample & 4372 & 2753 & & & & \\
\hline Chi-square & 4987.78 & 2888.9 & & & & \\
\hline
\end{tabular}


Alemayehu and Alem: Macro policy reform, labour market, poverty and...

\begin{tabular}{lrr}
\hline Pseudo R2 & 0.4476 & 0.4296 \\
\hline
\end{tabular}

Note $^{*} \quad p<0.05 ;{ }^{* *} p<0.01 ; \ddagger p<0.001$

\subsection{Simulation results}

The simulation involves computation of mean incomes and measures of inequality for the distribution obtained by replacing the estimated parameters of the Fourth Round Survey (2000) with those estimated from the First Round Survey (1994). Then we would compare the simulated values with the actual for the year 2000. The first set of simulations involves imposing the coefficients of the earning equations and the variance of error terms of the First Round on that of the Fourth Round. The results from this exercise done separately for wage and self-employment sectors and jointly for both sectors are reported below.

\section{Simulation I: Effect of change in structure of returns}

Let us first look at the impact of imposing the structure of returns from 1994 on the data of 2000. Imposing the 1994 structure (parameters) of returns in the wage sector leads to a fall in individual earnings, with mean earnings falling by about 13 percent and median incomes by about 15 percent. While this simulation leads to a decline in earnings for all earnings categories, the decline is higher in lower income categories, as can be seen from the decline of 20 and 18 percent in the $10^{\text {th }}$ and $25^{\text {th }}$ percentiles of individual earnings (see Table 12). This simulation also leads to an increase in inequality in wage earnings, with the magnitude of change in the alternative indices of inequality ranging from 3 to 14 percent. Thus, if the structure of returns observed in 1994 were to prevail in 2000 , the levels of income in the wage sector would have been lower. This implies that growth that accompanied the reform was favouring this category of workers in general and the relatively poor within this category in particular - here the reform was pro-poor.

Imposing the structure (or parameters) of earnings in the self-employment sector from 1994 on the 2000 data has effects that are opposite to what was observed in the wage sector (see Table 12). If the structure of returns observed in 1994 were to prevail in 2000 , the levels of income in the self-employment sector would have been higher - with mean income being about 24 percent higher and median income about 46 percent higher. Since relatively higher percentage increments of the selfemployment sector occur at lower levels of income, inequality declines. Alternative indicators of inequality show a decline ranging between 2 and 15 percent, with indicators that are more sensitive to changes at the extremes declining by larger magnitudes. Thus, the reform and the accompanied growth were not pro-poor in the self-employment sector. 
While the statistics presented above help gauge the general directions of the differences between the counterfactual and actual distributions, they fall short of our goal of comparing the distributions throughout the range of values they take. To this end, we supplement the above with kernel density estimates. The Figures in 6 below show kernel density estimates of counterfactual and actual distributions of earnings in the two sectors. The graphs confirm what the summary statistics have shown: in the wage sector, the distribution of counterfactual earnings is at every point to the left of the actual distribution. That is, the counterfactual involves moving a slash of the actual distribution from the right half of the distribution (the high-income end) to the left half (the low-income end). This corresponds to the observation that imposing the 1994 structure of earnings in the wage sector in the year 2000 leads to declines in all quintiles of income. While the general picture is similar in self-employment, the conclusion is less-clear cut as the curves cross each other more than once, with the density of the counterfactual being higher at first, then lower, then higher, then again lower than the actual distribution (see Figure 6).

\section{Table 12: Simulating effects of observable factors on individual earnings ${ }^{6}$}

\begin{tabular}{lcclrrr}
\hline \multirow{2}{*}{ Earnings (Birr) } & \multicolumn{2}{c}{$\%$ change importing: } & & \multirow{2}{*}{ Inequality } & \multicolumn{2}{c}{ \% change importing: } \\
\cline { 2 - 3 } \cline { 5 - 6 } & \multicolumn{1}{c}{$\boldsymbol{\beta}_{\mathbf{w}}$} & $\boldsymbol{\beta}_{\mathbf{s}}$ & & \multicolumn{1}{c}{$\boldsymbol{\beta}_{\mathbf{w}}$} & \multicolumn{1}{c}{$\boldsymbol{\beta}_{\mathbf{s}}$} \\
\hline Mean earnings & -12.6 & 23.51 & & Gini coefficient & 3.15 & -3.23 \\
10th percentile & -20.36 & 46.21 & & Gen entropy $(\varepsilon=-1)$ & 14.45 & -15.11 \\
25th percentile & -17.61 & 49.95 & & Gen entropy $(\varepsilon=0)$ & 8.3 & -8.68 \\
50th percentile & -14.79 & 46.11 & & Theil index & 7.08 & -9.82 \\
75th percentile & -13.05 & 36.39 & & Gen entropy $(\varepsilon=2)$ & 8.64 & -18.44 \\
90th percentile & -11.58 & 26.21 & & Std dev of loges & 4.62 & -2.72 \\
\hline
\end{tabular}

Figure 6(a) and (b): Kernel density estimates of earnings by sector of employment

\footnotetext{
${ }^{6}$ The columns " $\beta_{\mathrm{w}}$ " and " $\beta_{\mathrm{s}}$ " present results of simulation obtained by imposing estimated (year 1994) coefficients of earnings equations for the wage and self-employment sectors, respectively. The column labelled " $\beta_{W s}$ " present results of simulation imposing estimated coefficients of earnings equations for both sectors.
} 

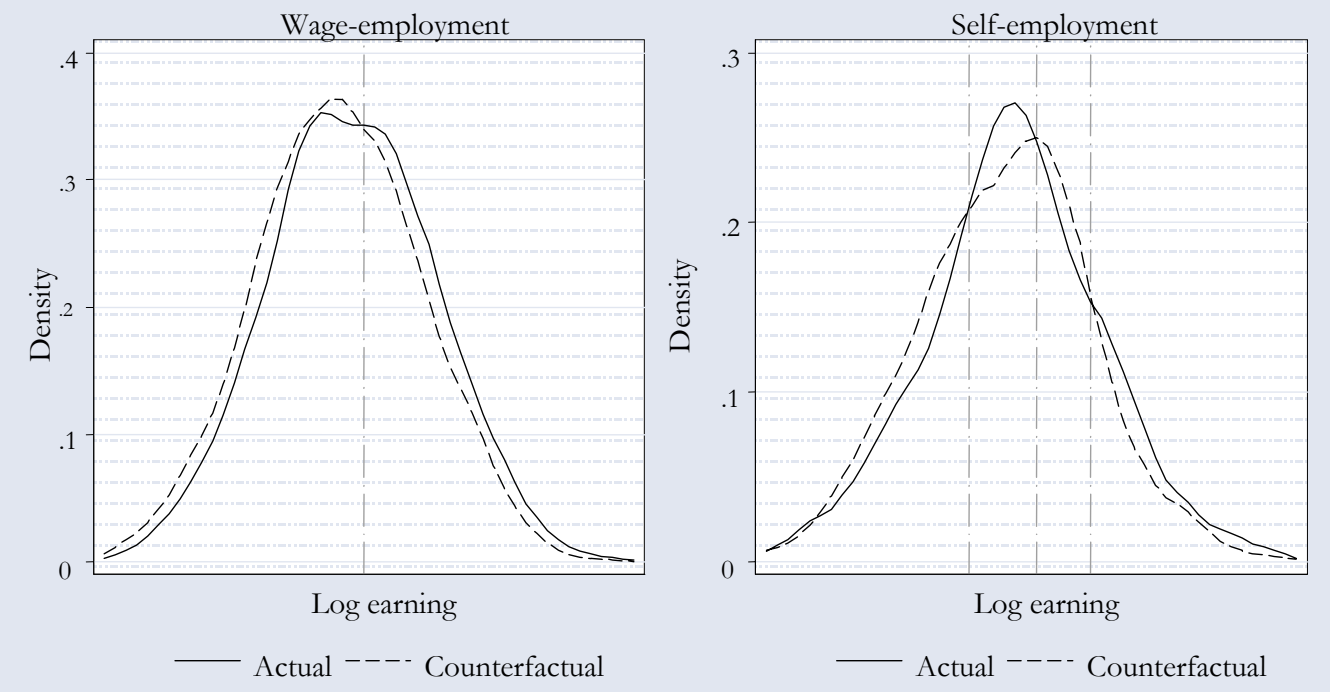

Figure 6(c): Kernel density estimates of percapita household income 


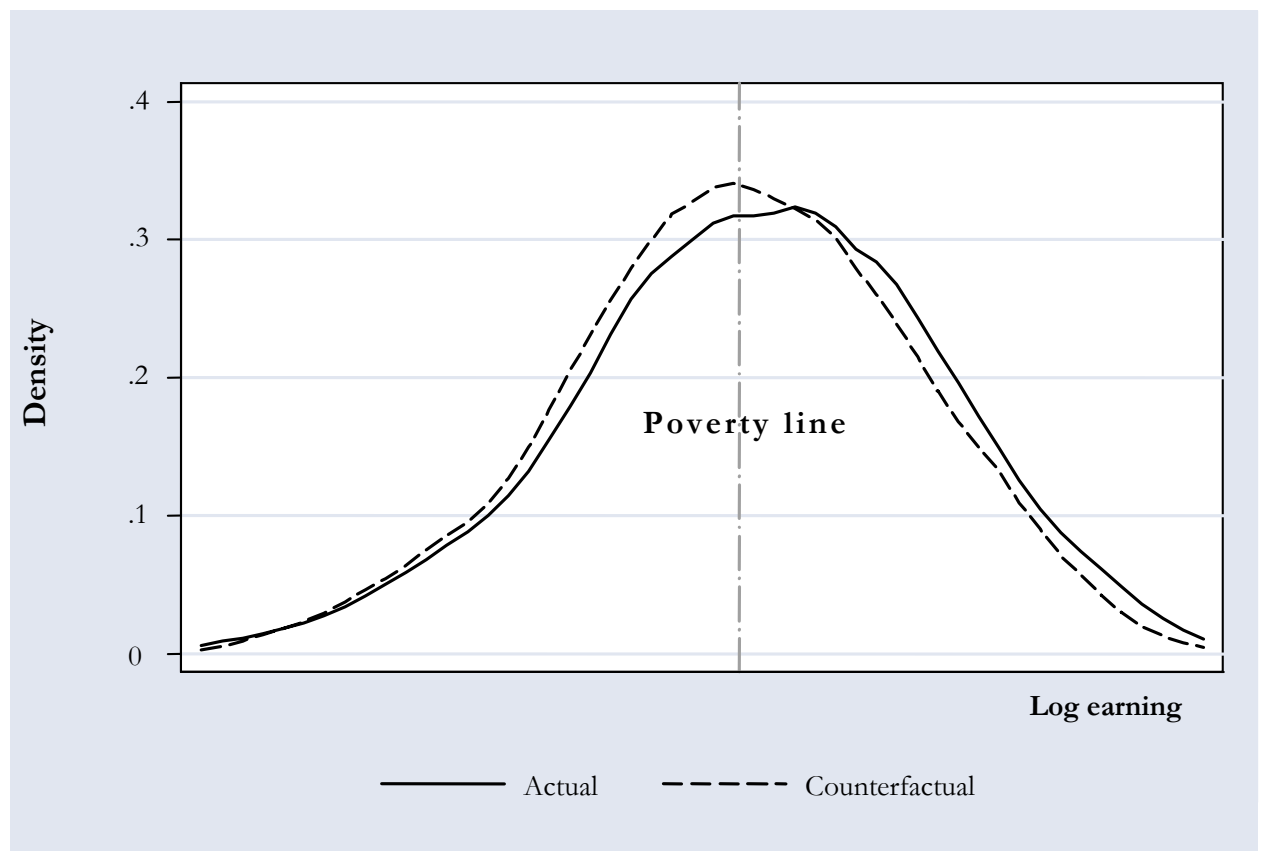

Table 13: Simulating observable determinants of earnings ${ }^{7}$

\begin{tabular}{|c|c|c|c|c|c|c|c|}
\hline \multirow[b]{2}{*}{ Earnings (Birr) } & \multicolumn{3}{|c|}{$\%$ changes importing } & \multirow[b]{2}{*}{ Poverty levels } & \multicolumn{3}{|c|}{$\%$ changes importing } \\
\hline & $\beta_{w}$ & $\beta_{S}$ & $\beta$ ws & & $\beta_{w}$ & $\beta_{s}$ & $\beta_{w s}$ \\
\hline Mean earnings & -7.8 & 8.45 & 1.21 & Headcount ratio & 7.81 & -3.11 & 4.55 \\
\hline 10th percentile & -6.73 & 6.09 & -1.15 & Poverty-gap ratio & 9.05 & -4.71 & 4.59 \\
\hline 25th percentile & -8.6 & 5.3 & -4.38 & FGT, $\alpha=2$ & 9.43 & -5.78 & 4.01 \\
\hline 50th percentile & -9.86 & 4.2 & -5.87 & Watts index & 9.17 & -6.06 & 3.45 \\
\hline 75th percentile & -8.84 & 5.33 & -3.8 & Sen & 8.6 & -4.42 & 4.27 \\
\hline 90th percentile & -9.09 & 7.88 & -0.46 & & & & \\
\hline \multicolumn{8}{|l|}{ Inequality } \\
\hline Gini coefficient & 1.24 & 1.96 & 3.83 & & & & \\
\hline Gen entropy $(\varepsilon=-1)$ & -1.5 & 0.62 & 1.43 & & & & \\
\hline Gen entropy $(\varepsilon=0)$ & 1.6 & 3.17 & 6.42 & & & & \\
\hline Theil index & 4.17 & 5.88 & 11.46 & & & & \\
\hline Gen entropy $(\varepsilon=2)$ & 9.98 & $\begin{array}{r}12.3 \\
2\end{array}$ & 22.98 & & & & \\
\hline Std dev of loges & -0.46 & 0.15 & 0.43 & & & & \\
\hline Coef of variation & 4.79 & 5.87 & 10.8 & & & & \\
\hline
\end{tabular}

\footnotetext{
${ }^{7}$ The columns " $\beta_{W}$ " and " $\beta_{S}$ " present results of simulation obtained by imposing estimated coefficients of earnings equations for the wage and self-employment sectors, respectively. The column labelled " $\beta_{W s}$ " present results of simulation imposing estimated coefficients of earnings equations for both sectors.
} 
The poverty and inequality profiles corresponding to the above two sets of simulations are shown in Table 13. The counterfactual distribution of household incomes provide poverty and inequality indicators consistent with the underlying (counterfactual) distribution of labour incomes. When the structure of returns from the wage sector is imposed alone, mean household incomes fall by about 8 percent and median incomes fall by about 10 percent. Correspondingly, the head count ratio rises by about 8 percent and the other indicators of poverty rise by similar magnitudes. The indicators of inequality did also show increasing inequality, though the magnitudes are smaller. When the 1994 structure of returns for observed factors in selfemployment is imposed alone, the level of household incomes rise, indicators of poverty fall, and that of inequality rise.

As these two simulations led to changes in opposite directions, then their effects would cancel each other out if we execute them simultaneously. That is what is observed in the last column of Table 13. When the 1994 structure of returns for both wage and self-employment sectors is imposed on the data of the year 2000 simultaneously, the level of incomes declines, but by magnitudes less than when the structure of returns for the wage sector was imposed alone, since part of the negative effect is counteracted by the rise in (counterfactual) self-employment incomes. Poverty is higher, again by magnitudes less than when returns in the wage sector are imposed alone. The effect of changes in the wage sector dominates because wage employment accounts for a much larger share of employment and incomes (is about $60 \%$, see Table 3). The implication for the impact of the liberalization policy is that it favoured the wage earners but not the self-employed, the aggregate effect overall being largely in line with the positive change observed in the wage-earning sector.

\section{Simulation II: Effects of Unobservable Determinants of Earnings}

The residuals in Mincerian earnings equations represent returns to labour accountable for unobserved factors that affect wages, and variance of the error terms represent inequality in wages due to these unobserved factors. Running simulations by importing residual variances from 1994 causes almost no change in the level of earnings. Relatively higher effects are observed on the indicators of inequality; with inequality being marginally lower in the counterfactual distribution, however. When the simulation is run using the returns to both observed and unobserved characteristics from 1994, it turns out that the effect of changes in observed characteristics is the dominant cause for any changes between 1994 and 2000. (see Table 16)

Changes in poverty and inequality associated with the above simulations are shown in Table 15. The marginal changes in individual incomes in the two sectors tend to cancel out each other such that the net effect on poverty is negligible. Though the 
effect on inequality is relatively higher, it is much smaller than what was observed when we imposed the structure of returns for observed characteristics.

Table 15: Effects of non-observables: Simulating the effects of nonobservable determinants of earning ${ }^{8}$

\begin{tabular}{|c|c|c|c|c|c|c|c|}
\hline \multirow{2}{*}{ Earnings (Birr) } & \multicolumn{3}{|c|}{$\%$ changes imposing } & \multirow{2}{*}{ Poverty levels } & \multicolumn{3}{|c|}{$\%$ changes imposing } \\
\hline & $\sigma_{94, w}$ & $\sigma_{94, \mathrm{~S}}$ & $\sigma_{94, w s}$ & & $\sigma_{94, w}$ & $\sigma_{94, \mathrm{~S}}$ & $\sigma_{94, \mathrm{Ws}}$ \\
\hline Mean earnings & 1.37 & -1.76 & -0.73 & Headcount ratio & -0.25 & -0.0910 & -0.17 \\
\hline 10th percentile & -0.67 & 0.24 & -0.34 & Poverty-gap ratio & 0.06 & -0.0268 & -0.30 \\
\hline 25th percentile & -0.08 & 0.58 & 0.55 & FGT, $\alpha=2$ & 0.20 & -0.0394 & -0.26 \\
\hline 50th percentile & 0.45 & 0.34 & 0.23 & Watts index & 0.10 & -0.1425 & -0.43 \\
\hline 75th percentile & 0.52 & -0.77 & 0.04 & Sen & -0.05 & -0.0812 & -0.22 \\
\hline 90th percentile & 2.57 & -1.35 & -0.19 & & & & \\
\hline Inequality & $\sigma_{94, w}$ & $\sigma_{94, \mathrm{~s}}$ & $\sigma_{94, w s}$ & & & & \\
\hline Gini coefficient & 0.48 & -1.0156 & -0.70 & & & & \\
\hline Gen entropy $(\varepsilon=-1)$ & 1.24 & -3.35 & -2.49 & & & & \\
\hline Gen entropy $(\varepsilon=0)$ & 1.12 & -2.08 & -1.40 & & & & \\
\hline Theil index & 0.57 & -3.00 & -2.33 & & & & \\
\hline Gen entropy $(\varepsilon=2)$ & -1.20 & -6.25 & -5.38 & & & & \\
\hline Std dev of loges & 0.56 & -0.67 & -0.41 & & & & \\
\hline Coef of variation & -0.55 & -3.02 & -2.60 & & & & \\
\hline
\end{tabular}

Combining the two simulations above, the first conclusion we draw is that changes in poverty are dominated by the effect of changes in observed characteristics (see Table 8). Second, the simulations lead to larger percentage changes in both wage and individual self-employment incomes. Yet, their effect on household-level income and poverty is not as strong as the changes in both categories of income, especially of the wage income, that result from the simulations. In terms of inequality, imposing the 1994 parameters of the wage sector led to slight increases in inequality. Imposing the 1994 parameters of the self-employment sector, on the other hand, led to a rise in inequality, which is larger magnitude. As a result, inequality changed along the change in the self-employment sector households (see Table 16).

A notable point that turns up at this juncture is the fact that incomes of the poorest deciles seems to have been affected the least by the changes in the structure of earnings (though this differs across wage and self-employed households). This is

\footnotetext{
${ }^{8}$ The columns " $\sigma_{w}$ " and " $\sigma_{s}$ " present results of simulation obtained by imposing (year 1994) standard deviation of the error term of earnings equations for the wage and self-employment sectors, respectively. The column labelled " $\sigma_{w s}$ " present results of simulation by imposing (year 1994) standard deviation of error terms of earnings equations for both sectors.
} 
consistent with the literature that finds the poorest to be least able to adjust to changes in the economic environment. All other income groups seem to have been affected more or less uniformly, with their incomes declining roughly uniformly by about 8 percent when the structure of returns that prevailed in 1994 is imposed.

Table 16: Effects of changes in returns to labour: Simulating total changes in structure of returns ${ }^{9}$

\begin{tabular}{|c|c|c|c|c|c|c|c|}
\hline \multirow{2}{*}{ Earnings (Birr) } & \multicolumn{3}{|c|}{$\%$ change importing } & \multirow{2}{*}{ Inequality } & \multicolumn{3}{|c|}{$\%$ change importing } \\
\hline & $\overline{\beta, \sigma_{W}}$ & $\overline{\beta, \sigma_{s}}$ & $\beta,, \sigma_{\mathrm{ws}}$ & & $\overline{\beta, \sigma_{w}}$ & $\beta, \sigma_{s}$ & $\bar{B}, \sigma_{w s}$ \\
\hline Mean earnings & -8.4 & 9.34 & 1.43 & Gini coefficient & 0.95 & 2.43 & 4.08 \\
\hline $10^{\text {th }}$ percentile & -6.17 & 5.8 & -0.94 & Gen entropy $(\varepsilon=-1)$ & -2.73 & 2.18 & 1.76 \\
\hline $25^{\text {th }}$ percentile & -8.3 & 5.23 & -4.28 & Gen entropy $(\varepsilon=0)$ & 0.85 & 4.22 & 6.83 \\
\hline $50^{\text {th }}$ percentile & -9.98 & 4.25 & -6.08 & Theil index & 3.65 & 7.39 & 12.66 \\
\hline $75^{\text {th }}$ percentile & -9.46 & 5.52 & -4.23 & Gen entropy $(\varepsilon=2)$ & 9.62 & 15.55 & 26.43 \\
\hline $90^{\text {th }}$ percentile & -10.05 & 8.43 & -1 & Std dev of loges & -0.87 & 0.49 & 0.38 \\
\hline & & & & Coef of variation & 4.61 & 7.35 & 12.31 \\
\hline
\end{tabular}

\begin{tabular}{lrrr}
\hline Poverty levels & & & \\
\hline Headcount ratio & 7.92 & -3.15 & 4.68 \\
\hline Poverty-gap ratio & 8.9 & -4.64 & 4.5 \\
\hline FGT, $\alpha=2$ & 9.1 & -5.64 & 3.84 \\
\hline Watts index & 8.84 & -5.89 & 3.31 \\
\hline Sen & 8.49 & -4.37 & 4.25 \\
\hline
\end{tabular}

The second notable point is the fact that the magnitude of change has been very small. Though some fundamental changes in macroeconomic policies and performance are known to have occurred in the 1990's, their effect on the structure of returns, and hence household welfare, have been, on the average, quite marginal.

\section{Simulation III: The Effect of Participation and Occupational Choice}

Changes in the pattern of occupational choice ( $\beta$ oc) account for a decline of about 6 percent (or 2.79 percentage points) in headcount ratios. That is, if the pattern of occupational choice observed in 1994 was to prevail in 2000 , headcount ratio of poverty would have been 44.44 percent instead of the observed level of 47.23 percent. Thus, the reform was strongly associated with a change in occupation choice that led to worsening poverty condition. This effect would have been strong had it not been to the positive gain

\footnotetext{
${ }^{9}$ The columns labelled " $\beta, \sigma_{w}$ " and " $\beta, \sigma_{s}$ " present results of simulation obtained by imposing parameters (coefficients and standard deviation of error terms) from earnings equations for the wage and selfemployment sectors, respectively. The column labelled "with $\beta, \sigma_{w s}$ " present results of simulation obtained by imposing parameters of earnings equations for both sectors.
} 
in earning by households in the wage earning category, showing only a less than half percent increase in poverty owing to the reform.(see Table 17).

Table 17: Effects of changes in occupational choice: Simulating poverty and inequality in household per capita income

\begin{tabular}{|c|c|c|c|c|c|c|c|c|c|}
\hline \multirow{2}{*}{$\begin{array}{c}\text { Earnings } \\
\text { (Birr) }\end{array}$} & \multicolumn{4}{|c|}{$\%$ change of imposing $1994:{ }^{10}$} & \multirow[b]{2}{*}{ Inequality } & \multicolumn{4}{|c|}{$\%$ change of importing 1994: } \\
\hline & ßoc & $\begin{array}{l}\text { With } \\
\beta, \sigma_{w}\end{array}$ & $\begin{array}{l}\text { With } \\
\beta, \sigma_{\mathrm{s}}\end{array}$ & $\begin{array}{l}\text { With } \\
\beta, \sigma_{\mathrm{ws}}\end{array}$ & & ßoc & $\begin{array}{l}\text { With } \\
\beta, \sigma_{\mathrm{w}}\end{array}$ & $\begin{array}{l}\text { With } \\
\beta, \sigma_{\mathrm{S}}\end{array}$ & $\begin{array}{l}\text { With } \\
\beta, \sigma_{w s}\end{array}$ \\
\hline Mean earnings & 16.54 & -2.83 & 9.89 & 11.64 & $\begin{array}{l}\text { Gini } \\
\text { coefficient }\end{array}$ & 4.51 & 0.59 & -1.59 & 4.65 \\
\hline 10th percentile & -1.29 & -11.82 & 17.69 & 3.01 & $\begin{array}{l}\text { Gen entropy } \\
(\varepsilon=-1)\end{array}$ & 16.97 & 18.39 & 7.13 & 7.07 \\
\hline 25th percentile & 7.71 & -4.67 & 11.31 & -0.48 & $\begin{array}{l}\text { Gen entropy } \\
(\varepsilon=0)\end{array}$ & 10.54 & 4.74 & -1.92 & 8.24 \\
\hline 50th percentile & 9.18 & -6.06 & 13.42 & 1.83 & Theil index & 13.23 & -1.95 & -6.56 & 11.03 \\
\hline 75th percentile & 13.57 & 2.01 & 13.87 & 3.57 & $\begin{array}{l}\text { Gen entropy } \\
(\varepsilon=2)\end{array}$ & 24.45 & -12.01 & -15.82 & 13.16 \\
\hline 90th percentile & 7.93 & -2.17 & 17.39 & 15.19 & $\begin{array}{l}\text { Std dev of } \\
\text { loges }\end{array}$ & 4.24 & 5.2 & 1.18 & 1.8 \\
\hline \multicolumn{10}{|l|}{ Poverty levels } \\
\hline Headcount ratio & -5.91 & 4.15 & -6.92 & -0.44 & & & & & \\
\hline $\begin{array}{l}\text { Poverty-gap } \\
\text { ratio }\end{array}$ & -5.52 & 6.74 & -7.71 & -3.45 & & & & & \\
\hline FGT, $\alpha=2$ & -4.62 & 9.98 & -9.12 & -4.87 & & & & & \\
\hline Watts index & -4.29 & 11.52 & -8.54 & -4.92 & & & & & \\
\hline Sen & -5.2 & 7.07 & -8.01 & -2.59 & & & & & \\
\hline
\end{tabular}

When parameters of occupational choice model (ßoc) are imposed along with parameters of the earnings equation for the wage sector, then the direction of change is reversed and we observe a fall of about 6 percent in median incomes and a rise of 4 percent in head count ratios. When combined with the parameters of earnings equations for the self-employment sector, on the other hand, the direction of change is reinforced and we observe a larger increase in incomes and a larger decline in indicators of poverty.

When all estimated parameters of 1994 (occupational choice, returns to labour in the wage sector, and returns to labour in the self-employment sector) are impose on the data of the year 2000 , the results are dominated by the (positive) changes in reducing poverty

\footnotetext{
${ }^{10}$ The column labelled $\beta_{\mathrm{oc}}$ presents results of simulation by imposing (year 1994) estimated coefficients from the occupational choice model. The columns labelled "with $\beta, \sigma_{w}$ " and "with $\beta, \sigma_{s}$ " present results of simulation obtained by imposing parameters from earnings equations for the wage and self-employment sectors, respectively, in addition to parameters of the occupational choice model. The column labelled "with $\beta, \sigma_{w s}$ " present results of simulation obtained by imposing parameters of earnings equations for both sectors and parameters of the occupational choice model.
} 
in the wage sector.(see Table 17). The latter basically implies that the reform was largely associated with a decline in mean income and inequality, and an increase in poverty.

\section{Simulation IV: Effect of Exogenous Variables}

In this section, we will attempt to capture the effect of change in the distribution of variables in the right-hand side of the income-determination and occupational-choice equations. The variables are exogenous in the sense that they were not modelled in our set of equations in any structural sense. The first variable in this category is sector of wage employment - public versus private. One of the major concerns during periods of stabilization and structural adjustment involves the effect of lower public sector employment (re-trenchermen of workers) that is not matched by rising employment in the formal private sector. It has been argued that retrenchment in the public sector coupled with lack of alternative productive employment during stabilization and structural adjustment has led not only to higher unemployment but also to increasing 'informalization' of the economy. As a large part of the informal sector involves participation in low-productivity/low-remuneration activities, increasing 'informalization' is associated with rising poverty.

In an attempt to at least partially capture this effect, we obtained counterfactual year 2000 wage incomes by imposing the share of public-sector employment observed in 1994 on the year 2000's dataset. Two sets of simulations were undertaken. In the first set, we changed the share of public-sector employment to reflect the pattern observed in 1994 while keeping the structure of returns from 2000. In the second, we imported the share of public-sector employment as well as the structure of returns from 1994. The results are shown in Table 18.

The outcomes of the first set of simulations (Table 18) show that the first deciles of the distribution reaffirms the conventional wisdom that a decline in public-sector employment is associated with declining incomes. The outcomes also indicate a decline in incomes in the second- (higher) half of the distribution - the $75^{\text {th }}$ and $90^{\text {th }}$ percentiles that show a decline of about 5 and 4 percent, respectively. The $25^{\text {th }}$ and $50^{\text {th }}$ percentile would have seen a decline in their income had it not been for the change in the share of the public sector share associated with the liberalization. When this is combined with changes in earning conditions during the period, the situation is virtually reversed. This suggests that the rise in returns to labour during the ear of liberalization more than offset the impact of falling share of public sector employment. This can be the result of higher pay rises for higher income groups in the public sector, better opportunities in private sector employment for them, or both. The opposite directions of change above and below the median under the first set of 
simulations led to a rise in inequality, with Gini coefficient rising by about 3 percent and other indicators by more. Headcount ratios as well as other indicators of poverty show a corresponding rise of about 2 percent in the simulation - indicating that liberalization is associated with a decline in both inequality and poverty owing to changes in sectoral share of employment as well as the return to labour (see Table 18).

Table 18: Effects of the structure of wage employment

\begin{tabular}{|c|c|c|c|c|c|}
\hline & \multirow{3}{*}{$\begin{array}{l}\text { Actual } \\
(2000)\end{array}$} & \multicolumn{4}{|c|}{ Imposing 1994 share of public-sector: } \\
\hline & & \multicolumn{2}{|c|}{ Only } & \multicolumn{2}{|c|}{ With $\beta_{W}, \& \sigma_{W}{ }^{1 T}$} \\
\hline & & Level & $\%$ change & Level & $\%$ change \\
\hline \multicolumn{6}{|l|}{ Earnings (Birr) } \\
\hline Mean earnings & 137.63 & 142.88 & 3.81 & 133.02 & -3.35 \\
\hline $10^{\text {th }}$ percentile & 13.96 & 14.01 & 0.36 & 13.20 & -5.44 \\
\hline $25^{\text {th }}$ percentile & 33.59 & 32.55 & -3.10 & 31.27 & -6.91 \\
\hline $50^{\text {th }}$ percentile & 74.97 & 72.12 & -3.80 & 66.26 & -11.62 \\
\hline $75^{\text {th }}$ percentile & 157.87 & 166.28 & 5.33 & 136.68 & -13.42 \\
\hline $90^{\text {th }}$ percentile & 319.52 & 333.44 & 4.36 & 299.57 & -6.24 \\
\hline \multicolumn{6}{|l|}{ Poverty levels } \\
\hline Headcount ratio & 47.23 & 48.17 & 1.99 & 51.29 & 8.60 \\
\hline Poverty-gap ratio & 24.63 & 25.12 & 1.99 & 26.48 & 7.51 \\
\hline FGT, $\alpha=2$ & 16.44 & 16.72 & 1.70 & 17.66 & 7.42 \\
\hline Watts index & 46.36 & 47.01 & 1.40 & 49.71 & 7.23 \\
\hline Sen & 32.10 & 32.70 & 1.87 & 34.69 & 8.07 \\
\hline \multicolumn{6}{|l|}{ Inequality } \\
\hline Gini coefficient & 0.5720 & 0.5891 & 2.99 & 0.5990 & 4.72 \\
\hline Gen entropy $(\varepsilon=-1)$ & 1.6418 & 1.7074 & 4.00 & 1.6665 & 1.50 \\
\hline Gen entropy $(\varepsilon=0)$ & 0.6625 & 0.6998 & 5.63 & 0.7120 & 7.47 \\
\hline Theil index & 0.6039 & 0.6488 & 7.44 & 0.6932 & 14.79 \\
\hline Gen entropy $(\varepsilon=2)$ & 0.9779 & 1.1043 & 12.93 & 1.2645 & 29.31 \\
\hline Std dev of loges & 1.2066 & 1.2247 & 1.50 & 1.2079 & 0.11 \\
\hline Coef of variation & 1.3946 & 1.4871 & 6.63 & 1.5914 & 14.11 \\
\hline
\end{tabular}

Note: $\beta_{w}, \& \sigma_{w}$

The outcomes of the second set of simulations show that imposing the structure of returns from 1994 reinforces only the effect observed in the $25^{\text {th }}$ and $50^{\text {th }}$ percentile. Offsetting the effect on the other households. This shows the possibility of a decline in level of inequality and poverty in the year 2000 since the share of public-sector

\footnotetext{
${ }^{11} \beta_{\mathrm{W}}$ and $\sigma_{\mathrm{W}}$ stands for estimated coefficients and standard deviation of the error term in the wage determination equation. Hence, the results in these columns represent simulation results obtained by imposing parameters of the earnings equation for the wage sector.
} 
employment has changed from 1994 following liberalization. The decline in incomes in the second set of simulations applies to every part of the distribution and the magnitudes of change are significantly higher. This shows that changes in the structure of returns in the wage sector in general are more important in explaining the changes in poverty than changes in the structure of public sector wage employment.

The other 'exogenous' variables we considered are those that describe the characteristics of the activities of the self-employed. These are the (i) share of female household businesses (FHB), which accounts for a substantial portion of self-employment; (ii) the share of self-employed people who reported zero or negative income (NSEI); and, (iii) the share of businesses with one or more paid workers (NPW), which is a proxy for the size distribution of self-employment activities (see Table 19).

Table 19: Effect of exogenous variables affecting self-employment income

\begin{tabular}{lrrrrr}
\hline & \multicolumn{5}{c}{ Percent change of imposing the 1994: } \\
\cline { 2 - 6 } & FHB & NSEI & NPW & $\beta, \sigma_{\mathbf{S}}$ & \multicolumn{1}{c}{ All } \\
\hline Earnings (Birr) & & & & & \\
Mean earnings & -1.03 & 5.96 & -4.21 & 8.45 & 12.20 \\
$10^{\text {th }}$ percentile & -10.82 & -4.15 & -2.58 & 6.09 & 12.75 \\
$25^{\text {th }}$ percentile & -7.62 & -5.72 & 0.33 & 5.30 & 2.26 \\
$50^{\text {th }}$ percentile & -3.56 & -3.56 & -3.64 & 4.20 & 1.96 \\
$75^{\text {th }}$ percentile & -2.63 & -0.58 & -1.22 & 5.33 & 3.31 \\
90 percentile & -0.05 & 2.12 & -2.94 & 7.88 & 17.92 \\
Poverty levels & & & & & \\
Headcount ratio & 3.13 & 1.40 & 3.71 & -3.11 & -0.76 \\
Poverty-gap ratio & 5.48 & 1.87 & 3.25 & -4.71 & -2.07 \\
FGT, a=2 & 8.15 & 2.55 & 3.28 & -5.78 & -2.92 \\
Watts index & 7.40 & 2.52 & 4.62 & -6.06 & -3.30 \\
Sen & 5.58 & 1.99 & 3.55 & -4.42 & -1.81 \\
Inequality & & & & & \\
Gini coefficient & 1.78 & 5.17 & -1.05 & 1.96 & 4.88 \\
Gen entropy $(\varepsilon=-1)$ & 5.35 & 13.39 & 8.31 & 0.62 & 8.16 \\
Gen entropy $(\varepsilon=0)$ & 4.75 & 10.22 & -1.01 & 3.17 & 9.25 \\
Theil index & 4.01 & 16.21 & -4.07 & 5.88 & 12.04 \\
Gen entropy $(\varepsilon=2)$ & 6.69 & 33.07 & -9.18 & 12.32 & 17.36 \\
Std dev of loges & 2.41 & 2.59 & 1.30 & 0.15 & 2.39 \\
Coef of variation & 3.65 & 15.76 & -4.37 & 5.87 & 8.71 \\
\hline
\end{tabular}

\footnotetext{
${ }^{12}$ The column labeled FHB, NSEI and NPW present simulation results obtained by imposing the share of female household businesses, negative self-employment incomes, and businesses with one-or more paid workers observed in 1994. The column labeled $\beta, \sigma_{S}$ presents results of imposing the parameters of the earning equation for self-employment sector from 1994. The last column labelled "All" presents results obtained when all four sets of parameters from 1994 are imposed.
} 
As we noted before, the share of female household businesses was about 38 percent in 1994 and 37 percent in 2000. The share of self-employed people using paid labour was about 13 in 1994 and 12 in 2000, and the share of self-employed people reporting zero or negative income was about 1.0 percent in 1994 and 0.5 in 2000. The results from the simulations of imposing the 1994 parameters corresponding to these variables result in lower levels of income and higher poverty rates (Table 19). Thus, the net effect of the changes in these variables is to counteract the effect of the change in the structure of returns.

\section{Conclusions}

This study noted that despite the deployment of macro policies to address problems of poverty and inequality in African countries in general and Ethiopia in particular, we know little about the channels through which the deployed macro policies are supposed to affect poverty and inequality. Ethiopia embarked in a comprehensive liberalization policy (the reform or SAPs) in 1992. In this study we hypothesized that these policies had an effect on poverty and inequality. We further considered that the effect of these policies could be inferred from the change in the structure of labour market as it is one of the most important channels through which macro polices may affect poverty and inequality. This underscores the need to examine the letter closely. We have used Ethiopian urban household survey data for the year 1994 and 2000 to address this issue.

As the year 1994 was the aftermath of the period that corresponds to the launching of structural adjustment program of the country, one would expect larger changes in income levels, poverty and inequality since then, especially in urban areas. This expectation, however, is not borne out by our data and aggregate indicators of poverty and inequality. Between 1994 and 2000, poverty headcounts declined only slightly from about 52 percent to about 47 percent. Since there was no change in mean per capita household income (which was about Birr 137.00 in both periods), the observed slight decline in headcount ratios seems to be the results of redistribution that favoured lower income groups. We also noted that since the observed changes in mean and median incomes are statistically insignificant, there is a need to focus on explaining why incomes remained stable at a time of fundamental changes in macroeconomic policy environment.

We have used both data exploratory analysis as well as earning and occupational choice modelling, together with counterfactual simulation, to investigate this issue. The study showed that the absence of change in aggregate measure of poverty and 
inequality hides an enormous change when the analysis is carried across different income categories and sectors. Using micro simulation analysis, we noted that changes in incomes of different categories of urban households move in opposing directions and cancel out each other when an aggregate poverty and inequality indicator is computed. The study has show that although there seem to be limited change in poverty and inequality at aggregate level, there is significant change within and across categories of households. The distribution of household incomes is found to depend on the structure of returns to labour and on the occupational choice the households made.

The estimated result of the models used and the micro-simulation analysis conducted shows that. First, the mean minimum income in the wage sector rose while it declined in the self-employment sector; this is consistent with the exploratory analysis conducted that preceded the modeling work. However, in the wage sector, there has been a decline between the years in the premiums associated with being male, being a public-sector employee as well the premiums associated with experience and the level of education. This may relate to the lack of incentive-compatible pay system in public sector. In the self-employment sector, over the reform period, the disadvantages arising from operating being female household businesses have become bigger, while the premiums associated with larger business have increased substantially. If female-headed business is a good proxy for the poor in the informal sector, as can be inferred from the exploratory analysis in this study, the reform is associated with relatively negative outcome for this group.

Second, the simulation analysis which is conducted by imposing the estimated parameters from the 1994 survey on the data of the year 2000, revealed that the change in aggregate poverty and inequality indicators is smaller while it varies across the two sector identified - wage and self-employment sectors. The effect of changes in the wage sector dominates because wage employment accounts for a much larger share of employment and incomes. The implication for the impact of the liberalization policy is that it favored the wage earners but not the self-employed, the aggregate effect overall being largely in line with the positive pattern in reducing poverty observed in the wage-earning sector. Within the latter sector, those in the lower echelons of the income bracket benefited more - in this sense, the growth was propoor.

Third, when the simulation is run using the returns to both observed and unobserved characteristics of the labour market from 1994, it turns out that the effect of changes in observed characteristics is the dominant cause for any changes between 1994 and 2000. The simulations led to larger percentage changes in both wage and individual self-employment incomes. Yet, their effect on household-level income and poverty is 
not as strong as the changes in both categories of income, especially of the wage income, that result from the simulations. In terms of inequality, imposing the 1994 parameters of the wage sector led to slight increases in inequality. Imposing the 1994 parameters of the self-employment sector, on the other hand, led to a rise in inequality, which is larger in magnitude. As a result, inequality changed along the change in the self-employment sector households.

Fourth, in terms of the effect of occupational choice, the micro-simulation exercise has shown that if the pattern of occupational choice observed in 1994 was to prevail in 2000 , headcount ratio of poverty would have been 44.44 percent instead of the observed level of 47.23 percent. Thus, the reform was strongly associated with a change in occupation choice that led to worsening of the poverty condition. This effect would have been strong had it not been to the positive gain in earning by households in the wage earning category, showing only a less than half percent increase in aggregate poverty level as measure by head count ratio.

Finally, the study highlighted the possible impact of the reform on the public sector (and other exogenous variables) and poverty. The related simulation shows that changes in the structure of returns in the wage sector in general are more important in explaining the changes in poverty than changes in the structure of public sector wage employment or other exogenous variables.

Perhaps the most important policy lesson from this study is the importance of understanding issue of distribution of income across income and occupational category in the context of drawing poverty reducing macro policies. Policy effectiveness with regard to poverty reduction could be achieved if we understand the workings of the labour market and how it affects both level and distribution of income. This is especially true since inequality is generally found to be positively associated with rising poverty. This study has offered such information. 


\section{References}

Alemayehu Geda (2005). Macroeconomic performance in the post-Derg Ethiopia, Journal of Northeast African Study, 8(1): 159-204.

Alemayehu Geda, Abebe Shimeles and John Weeks (2002). The pattern of growth, poverty and inequality in Ethiopia: Which way for a pro-poor growth? (A study prepared for Ministry of Finance and Economic Development (MoFED), Ethiopia)

Cárdenas, Mauricio, and Nora Lustig (eds.) (1998). Pobreza y Desigualdad en América Latina, Conference papers presented at the Annual Meeting of Latin American and Caribbean Economists (LACEA), Bogota: TM Editors, Fedesarrollo, LACEA, Colciencias.

Contreras, Dante G., Sergio Urzúa S. and David Bravo U. (2002). Poverty and inequality in Chile 1990-1998: Learning from microeconomic simulations.

Fereira, Francisco H.G., and Julie Litchfield (1998). Educación o inflación? Papel de los factores estructurales y de la inestabilidad mácro-económica en la explicación de la desigualdad en Brasil en la década de los ochenta", in Mauricio Cárdenas and Nora Lustig (eds.): 101-132.

Ferreira, Francisco H.G. and Phillippe George Leite (2004). Educational expansion and income distribution: A micro-simulation for Ceará.

Frenkel, Roberto, and Martín González Rozada (2000). Liberalización del balance de pagos. efectos sobre el crecimiento, el empleo y los ingresos en Argentina - Segunda parte". Buenos Aires: CEDES (mimeo).

Grimm, Michael (2004). A decomposition of inequality and poverty changes in the context of macro-economic adjustment: A Micro-simulation study for Côte d'Ivoire".

Jenkins, Stephen P. (1995). Accounting for Inequality Trends: Decomposition analyses for the UK, 1971-86, Economica (62):29-63.

Mookherjee, Dilip, and Anthony Shorrocks (1982). A decomposition analysis of the trend in UK income inequality", Economic Journal (92):886-902.

Paes de Barros, Ricardo (1999). Evaluando el impacto de cambios en la estructura salarial y del empleo sobre la distribución de renta, Rio de Janeiro, IPEA (mimeo).

Paes de Barros, Ricardo, and Philippe Leite (1999). O impacto da liberalizaçao sobre distribuiçao de renda no Brasil', Rio de Janeiro: IPEA (mimeo).

See Bigsten, A. and A. Shimeles (2005). Poverty and income distribution in Ethiopia: 19902000, Department of Economics, University of Gothenburg, mimeo.

Vos, R, Lance Taylor and R. Paes de Barros (2002). Economic liberalization, distribution and poverty: Latin America in the 1990s. Cheltenham: Edgard Elgar. 